\title{
1 Relating in situ hydraulic conductivity, particle size and relative \\ 2 density of superficial deposits in a heterogeneous catchment
}

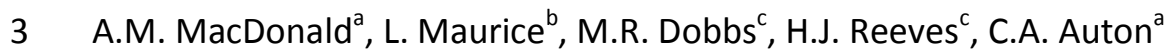

4

$5 \quad{ }^{a}$ British Geological Survey, Murchison House, West Mains Road, Edinburgh, EH9 3LA, UK

6 British Geological Survey, Maclean Building, Crowmarsh Gifford, Oxfordshire, OX10 8BB, UK

7 'British Geological Survey, Kingsley Dunham Centre, Keyworth, Nottingham, NG12 5GG, UK

9 Corresponding author: Alan MacDonald. Email: amm@bgs.ac.uk. Tel: +44 (0)131 6500389

Abstract

Estimating the permeability of superficial deposits is fundamental to many aspects of catchment

science, but can be problematic where insufficient in situ measurements are available from pumping

tests in piezometers. Consequently, common practice is to estimate permeability from the material description or, where available, particle size distribution using a formula such as Hazen. In this study, we examine the relationships between particle size, relative density and hydraulic conductivity in superficial deposits in Morayshire, Northern Scotland: a heterogeneous environment typical of many catchments subject to previous glaciations. The superficial deposits comprise glaciofluvial sands and gravels, glacial tills and moraines, raised marine sediments, and blown sands. Thirty-eight sites were investigated: hydraulic conductivity measurements were made using repeated Guelph Permeameter measurements, cone resistance was measured in situ with a Panda dynamic cone penetrometer; material descriptions were made in accordance with BS5930:1999; and disturbed samples were taken for particle size analysis. Overall hydraulic conductivity (K) varied from $0.001 \mathrm{~m} / \mathrm{d}$ to $>40 \mathrm{~m} / \mathrm{d}$; glacial till had the lowest $\mathrm{K}$ (median $0.027 \mathrm{~m} / \mathrm{d}$ ) and glacial moraine the highest $\mathrm{K}$ (median $30 \mathrm{~m} / \mathrm{d}$ ). However, within each geological unit there was great variability in measured hydraulic conductivity values. Multiple Linear regression of the data indicated that $\log d_{10}$ 
27 and relative density (indicated by cone resistance or BS5930:1999 soil state description) were

28 independent predictors of $\log \mathrm{K}$ and together gave a relationship with an $\mathrm{R}^{2}$ of 0.80 . Material 29 description using the largest fraction (e.g. sand or gravel) had little predictive power. Therefore, in 30 heterogeneous catchments, the permeability of superficial deposits is most strongly related to the

31 finest fraction (d10) and relative density of the material. In situ Guelph permeameter

32 measurements at outcrops with good geological characterisation provide an easy and reliable

33 method of determining the permeability of particular units of superficial deposits.

34 Keywords: Permeability; Superficial deposits, Particle Size, Permeameter, Relative density, Hydraulic 35 conductivity 


\section{1. Introduction}

Estimating the permeability of superficial deposits is fundamental to many aspects of catchment science and hydrogeology. It is critical to characterising groundwater/surface water interaction and in particular baseflow to upland rivers (e.g. Morrice et al., 1997; Soulsby et al., 2007); groundwater vulnerability assessments (Gogu RC and Dassargues 2000; Lake et al., 2003; Ó Dochartaigh et al., 2005); urban hydrogeology (Bruce and McMahon, 1996; Chilton, 1999); groundwater recharge (Lloyd et al., 1981; Cuthbert et al., 2009; Misstear et al. 2009; Griffiths et al., 2011) and increasingly for predicting and mitigating flooding (Macdonald et al., 2008). Where sufficiently permeable and saturated, superficial deposits form aquifers which can be developed for both private and public water supply (e.g. Maupin and Barber, 2005; MacDonald et al., 2005).

The most obvious, and reliable, way to estimate permeability is through testing the saturated portion of the aquifer using constant rate pumping tests in piezometers (e.g. Melville et al., 1991; Jones et al., 1992; Jones, 1993; Meinken and Stobar, 2003). However, there are a number of difficulties in relying solely on piezometers for characterising the permeability of superficial deposits: (1) superficial deposits are highly complex, and sufficient boreholes are not generally available for testing; (2) the deposits are often unsaturated (pumping tests are only applicable below the watertable); (3) permeability can be too low to measure easily with standard pumping tests (Jones, 1993; Renard, 2005); (4) the complexity of superficial sequences can mean that it is difficult to control which units are being tested, and (5) fine-grained material can smear borehole walls causing permeability to be underestimated (McKay et al., 1993). Various methods have been designed to directly measure in situ permeability within soil, for example disc permeameters and infiltrometers (Perroux and White, 1988; Angulo-Jaramillo et al,. 2000), constant head permeameter (Amoozegar 1989; Elrick et al. 1989); but these methods are rarely used below the top soil. 
Therefore, due to a lack of directly measured permeability data, surrogate information is used - for example particle size analysis (e.g. Song et al., 2009), or permeability is inferred from the geological description (e.g. McCloskey and Finnemore, 1996; Fogg et al., 1998; McMillan et al., 2000). The relationship between permeability and particle size is well established and has been used as a predictive tool since the $19^{\text {th }}$ century (e.g. Hazen, 1892; Schlichter, 1899). These relationships are still used today, and in a review of 19 studies of particle size and permeability Shepherd (1989) demonstrated the clear trend of increasing permeability with increasing particle size. $D_{10}$ (the particle diameter that $10 \%$ of the sample is finer than) is often seen as the best predictor of permeability and central to many formulae used for calculating permeability (e.g. Hazen, 1892; Kozeny, 1927; later modified by Carman, 1937, Carrier, 2003). However, many different methods predict permeability using particle size data. For example, Alyamani and Şen (1993) used the full distribution of particle sizes, rather than just the $D_{10}$; and Cronican and Gribb (2004) developed a method of determining permeability from particle size information in materials containing more than $70 \%$ sand. Permeability values derived from particle size analysis are different depending upon which formulae are used (Vuković and Soro, 1992; Milham and Howes, 1995; Odong, 2007; Song et al., 2009; Vienken and Dietrich, 2011). It is generally agreed that determining permeability using particle size analysis is best suited to loose sand and gravel dominated sediments and is less suited to deposits dominated by silt and clay (Vokovic and Soro, 1992; Chapuis, 2004).

It is clear that particle size alone does not determine permeability, and the wider factors controlling permeability are the subject of ongoing study. Permeability of unconsolidated deposits is affected by the particle shape, particle packing and degree of compaction (e.g. Sperry and Peirce, 1995; Koltermann and Gorelick, 1995). Permeability is much higher in loose sediments than in compact (dense) sediments, which have lower porosity and a less well developed network of interconnected voids (Summers and Weber, 1984; Taylor et al., 1990; Koltermann and Gorelick, 1995; Watabe et al., 2000; Hubbard and Maltman, 2000; Mondol et al., 2007). These complicating factors are more 
significant in heterogeneous material, where the clay content, compaction and deformation of the deposits are variable. In many catchments, and in particular those that have been subject to glaciation, superficial deposits are highly heterogeneous and therefore it is often not appropriate to use standard particle size models to reliably predict permeability.

Scale effects, and ensuring that permeability measurements relate to the same material that engineering data (e.g. particle size analysis, relative density) have been collected for, provide additional problems for developing robust models. Removing material to carry out permeability measurements in a laboratory allows good control over the material on which the tests are being carried out, but compromises the in situ characteristics of packing and density. Removing the material as a core can partially overcome these issues, but the material needs very careful handling to avoid deformation; also if the material is taken as a core then normally only vertical permeability can be measured, and thus be limited by the lowest permeability layer within the sequence. In situ tests such as pumping tests or slug tests sample a larger area and often report higher permeabilities than laboratory tests, mainly due to the presence of fracturing (Daniel, 1989; Neuzil, 1994; SchulzeMakuch et al., 1999; Gierczak et al., 2006). This is particularly common within very low permeability till material (e.g. Hendry, 1982; Keller et al., 1988; Fredericia, 1990; McKay et al., 1993; Nilsson et al., 2001). If tills are not fractured, then scale effects are less of an issue (Keller et al., 1989).

In this study, we examine a variety of superficial deposits from Morayshire, Northern Scotland, measuring in situ saturated hydraulic conductivity, taking samples for particle size analysis, making soil descriptions, and measuring in situ cone resistance. The aim is to examine the relationships between particle size, relative density and hydraulic conductivity, and to determine how well the surrogate data predict hydraulic conductivity in this heterogeneous suite of deposits, typical of many catchments that were subject to Quaternary glaciations. 


\section{Study area}

110

111

The northeast coast of Scotland, between Inverness and Aberdeen, has interesting hydrology and geology, which have a significant impact on land use and society. Several major rivers flow northward from the Grampian highlands in the south towards the Moray Firth (Figure 1). These rivers are prone to flooding (McEwen and Werrity, 2007), and considerable effort and resource is being invested in developing flood alleviation schemes to protect the coastal towns of Elgin and Forres. Previous glaciation of this area has resulted in the formation of a coastal strip of flat land approximately $10-20 \mathrm{~km}$ wide. This ground is underlain by $10 \mathrm{~s}$ of metres of superficial deposits which form fertile soils and enable high-value agriculture. The coastal strip receives relatively little rainfall compared to the rest of Scotland $(<600 \mathrm{~mm})$ and groundwater is widely abstracted for agricultural and industrial use, and in some locations for public supply (Ó Dochartaigh et al., 2010). Characterising the permeability of the strata is fundamental to helping to predict and mitigate flooding, assess the risk of groundwater flooding, and also assess the potential of the superficial materials for sustaining large scale groundwater abstraction.

The area is underlain by a complex succession of Glacial and Post Glacial strata (Figure 1) that have mainly accumulated during the last 25,000 years. These range in thickness from a few to many tens of metres. The sandstone and ancient crystalline bedrock is generally concealed beneath a variable thickness of glacial till (Figure 1 and 2). Much of this till was laid down during the Main Late Devensian ice-sheet glaciation of Scotland, although some sandy tills and associated moraines in the coastal area were deposited by re-advances of a major fast-flowing glacier that occupied the Moray Firth after the surrounding uplands had become ice free. Most of the glacial tills crop out in steep river cliffs, where they are seen to be overlain by a considerable thickness of sand and gravel that were deposited by glacial meltwaters as the ice decayed. Mounds and ridges of poorly sorted cobble and boulder gravel were laid down in contact with the ice, whereas the well stratified sand 
and gravel that forms terraces up to $15 \mathrm{~m}$ in height on the flanks of the present valleys were deposited by meltwater rivers beyond the ice margins. In the coastal area meltwater flowed into what is now the Inner Moray Firth, where it mixed with seawater and laid down sandy and silty glaciomarine sediments many metres in thickness.

Much of the outcrop of the glacial, glaciofluvial and glaciomarine deposits is concealed by Post Glacial sediments (Figure 2). Along the coast, the glaciomarine sediments are largely buried beneath Post Glacial raised shoreline deposits of silt and sand, and both are locally concealed beneath extensive dunes of blown sand. Inland glacial, glaciolacustrine and glaciofluvial sediments have been reworked by rivers and streams to form spreads of sandy and gravelly alluvium and river terraces along the major valleys; silty lacustrine deposits and peat infill many ice scoured hollows and kettleholes, and blanket peat is still accumulating on the higher ground.

\section{Methods}

\subsection{General/Site selection}

Twenty-five sections of superficial deposits for which the geology is well characterised were selected in an area of approximately $250 \mathrm{~km}^{2}$ (Figure 1). The sites were chosen to include all the main types of superficial deposits present. Sections were between 2 and $20 \mathrm{~m}$ high, and at some sections several different types of superficial deposits were present and were sampled. Figure 3 shows a photograph of a typical section. In total, 38 different deposits were sampled at the 25 sections of which 14 were glacial tills, 3 were glacial moraines, 7 were glaciofluvial sands and gravels, 3 were glaciolacustrine deposits, 8 were raised marine deposits, and 3 were blown sand deposits.

Each site was visited by a team including a Quaternary geologist, hydrogeologist and engineering geologist. The Guelph permeameter was used to obtain an in situ measurement of the hydraulic 
conductivity of the deposits. The cone resistance of the material was measured in situ with a Panda dynamic cone penetrometer to give an indication of relative density, superficial deposit descriptions were made at the outcrop in accordance with BS5930:1999 (British Standards Institute, 1999a); and disturbed samples were taken for particle size analysis. At each site, in situ Guelph permeameter and Panda cone penetrometer measurements were carried at the same place within the outcrop and within the same material, which was then sampled for particle size analysis.

\subsection{Guelph permeameter field methods}

The Guelph permeameter measures the field saturated hydraulic conductivity of unsaturated deposits and involves measuring the volume of water required to maintain a steady-state constant head using a Mariotte bottle system constructed of plastic tubes (Figures 3 and 4, see Reynolds and Elrick (1985) for a full description of the apparatus and procedure). The major advantage of this type of test is that the material is in situ so a more representative volume of material can be tested than in the laboratory (Daniel, 1989). In this study, the one head method was used (Elrick et al., 1989; Reynolds et al., 1992) which should generally give results within $25 \%$ of the two head method. The permeameter used has an approximate quoted range of $10^{-7}$ to $10^{-4} \mathrm{~m} / \mathrm{s}$; however we found the permeameter to have repeatable results slightly outside this range and determined a practical range of 0.001 to $40 \mathrm{~m} / \mathrm{d}\left(1.2 \times 10^{-8}\right.$ to $\left.5 \times 10^{-4} \mathrm{~m} / \mathrm{s}\right)$. Others have also used the Guelph permeameter within this expanded range (e.g. Lee et al., 1985; Mohanty et al., 1995).

Six sections were sampled in September 2008 and the remaining sections were sampled in June 2009. At each measuring point a flat ledge was excavated into the exposure at least one metre below the soil (Figures 3 and 4). The ledge extended into the face ensuring that measurements were not affected by small scale fracturing at the edge of the ledge, or by the roots of any vegetation present at the top of the outcrop. A hole of constant diameter (which ranged from 5 to $6 \mathrm{~cm}$ between test sites) with a depth of 6 to $10 \mathrm{~cm}$ was excavated into the ledge. In clayey materials the 
walls were de-smeared using a sharp metal spoon and small wire brush (Bagarello et al., 1997). The Guelph Permeameter was placed in the hole immediately after excavation with a small packof 5 $10 \mathrm{~mm}$ pea gravel to prevent the sides of the hole collapsing. Water was released from the Guelph Permeameter to obtain a constant head of 4 to $5 \mathrm{~cm}$ in the hole. Gradations on the Guelph Permeameter were read at regular intervals to determine the rate of water input required to maintain the head. Readings were taken at intervals determined by the rate of water movement and varied from every 5 seconds to every 15 minutes depending upon the permeability of the deposit. In the highest permeability deposits measurements were made until the reservoir emptied, but in other deposits measurements continued until a regular rate of water input was consistently observed.

At most sampling locations a second measurement was made in the same deposit, and if there were substantial variations between the two measurements or some other problem (e.g. flooding, collapse, or cracking of the material surrounding the hole), a third measurement was made. The repeated measurements were made on a new ledge constructed at the same depth and into the same material as the first. Occasionally it was only possible to obtain one reliable measurement in a deposit type because of the geometry of the section, or because the permeability was below the measuring capacity of the permeameter. Hydraulic conductivity was calculated from the data using the software G-Perm1 which is based on the formulae outlined in Reynolds and Elrick (1985).

\subsection{Soil description field method}

Soil descriptions, in accordance with British Standards BS5930:1999 (British Standards Institution 1999a) and BS5930:1999 amendment 1 (British Standards Institution, 1999b), were made for all the superficial deposits encountered at each section by an engineering geologist. The standards systematically describe the state, structure, colour and the size and relative proportions of composite particles. Particular emphasis was given to the descriptions of soil state which directly 
describes relative density (for coarse soils) or is directly related to relative density (for fine soils).

205

206

207

208

209

210

211

212

213

214

215

216

217

218

219

220

221

222

223

Descriptions of fine soils were made in accordance with BS5930:1999 amendment 1 such that the soil state of silt and clay was described from very soft through soft, firm and stiff to very stiff. Descriptions of coarse soils were made in accordance with BS5930:1999 such that the soil state of sand and gravel was described from very loose through loose, medium dense, dense to very dense. Descriptions of all soil properties were based solely on field observation.

In order to allow the relationship between soil state and hydraulic conductivity to be quantified a Soil State Description Value (SSD) was derived. The coarse soil state descriptions were numerically ranked from 1 to 5 , very loose to very dense. The soil state descriptions for fine deposits were numerically ranked from 1 to 5 from very soft to very stiff.

\subsection{Particle size distribution sampling and analysis}

Large disturbed bulk samples were taken from each superficial deposit, at each location, in accordance with BS5930:1999 amendment 1 (British Standards Institution, 1999b). Large cobbles and boulders were not sampled due to limitations on the mass of material that could be obtained at each outcrop. Instead, a note of any omission of large cobbles and boulders was made for each sample where it occurred, and the mass percentage of cobbles and boulders was estimated and added to the soil description. The particle size distribution analysis data does not include particles larger than cobble size $(>200 \mathrm{~mm})$. The sample material was obtained adjacent to in situ test locations to ensure they were representative of the deposits tested by both the Guelph permeameter and Panda penetrometer.

Thirty-four samples were tested for particle size distribution in accordance with BS1377:Part 2:1990 (British Standards Institution, 1990) and Eurocode 7: Part 2 (2007). The analysis was undertaken using the wet sieving method. Where a significant fraction $(>10 \%)$ of material $<63 \mu \mathrm{m}$ remained, 
further analysis was undertaken to separate the silt and clay fraction. Fine particle analysis was undertaken, in accordance with Eurocode 7 (2007), by x-ray monitored gravity sedimentation using a Micromeritics SediGraph III. As part of the analysis the $d_{10}, d_{15}, d_{30}$ and $d_{60}$ for each sample was calculated, corresponding respectively to the $10^{\text {th }}, 15^{\text {th }}, 30^{\text {th }}$ and $60^{\text {th }}$ percentile of the particle size distribution.

\subsection{Panda penetrometer field methods}

Dynamic cone penetrometer measurements were undertaken for thirty deposits at 23 locations. This technique measures the in situ dynamic cone resistance (in megapascals - MPa) of the soil through which the cone is passing and is, therefore, directly related to the relative density of the deposit. The test was undertaken by driving a $4 \mathrm{~cm}^{2}$ steel cone on the end of a set of $0.5 \mathrm{~m}$ long threaded steel rods through the target deposit using a fixed weight hammer. The Panda2 measures the velocity of the hammer impact on the head of the rods and the depth of cone penetration in order to determine the dynamic cone resistance using a modified form of the Dutch Formula (Langton, 1999). The method can reach depths of up to $6 \mathrm{~m}$ in soils with a resistance up to $20 \mathrm{MPa}$. It is relatively lightweight $(20 \mathrm{~kg})$ and portable thereby making it ideal for testing soils in situ. A more detailed explanation of the Panda Penetrometer testing methodology and correlations with other dynamic and static cone penetration tests can be found in Langton (1999).

The thirty in situ Panda Penetrometer tests were carried out in two field seasons: Sept/Oct 2008 and June 2009. The tests were undertaken adjacent to the location of the Guelph permeameter tests to ensure the deposits tested were representative of those tested by the Guelph permeameter. However, tests were performed sufficiently far apart (in the order of $1-5 \mathrm{~m}$ ), in order to minimise the interference effects. Panda penetrometer tests were also not performed at the same time as Guelph permeameter so that vibration did not affect deposits being tested by the Guelph 
permeameter. At each location an initial attempt was made to test the entire exposed section by

253

254

257

258 probing from the top of the section to the base. Where this was not possible then a flat shelf or series of shelves were dug at appropriate intervals so as to intersect the target strata (Figure 5). The test was terminated once effective refusal was reached (where cone resistance was consistently $>20$ $\mathrm{MPa}$ ) or once the rod length was below the level of the exposed section. Where effective refusal occurred as the likely result of an isolated obstacle, such as a cobble or boulder, then a repeat test was conducted at the same level but offset by a few metres to avoid the obstacle. Where refusal occurred in dense and/or cobbly and bouldery strata (i.e. where obstacles were not isolated) then a second test was undertaken, where possible, on a flat excavated shelf or surface below the level of the dense and/or coarse stratum.

The dynamic cone resistance measured at each test location was recorded by the Panda2 unit as a single sounding. Examples of typical soundings from two sites are shown in Figure 6 . There is variability in the dynamic cone resistance measured by each separate hammer blow, which is to be expected in heterogeneous deposits. However, it is possible to correlate sections of the Panda sounding with separate layers identified as part of the geological descriptions made in the field. The median value of the section referring to the target geological unit was used in the analysis. Where more than one Panda test was undertaken in a deposit, the average was used.

\section{Results}

\subsection{Guelph permeameter results}

The field data produced consistent plots of water-level through time indicating the steady infiltration rate of water during the test required for analysis (Figure 7). Figure 8 shows that repeat samples in the same deposit type at the same outcrop give similar hydraulic conductivity $\left(R^{2}=0.9\right)$ indicating that the measurements are reproducible. For the 28 sample sites where 2 or more reliable hydraulic conductivity values were obtained, a mean hydraulic conductivity for the site was used for further 
analysis. Since Figure 8 indicates a high degree of reproducibility in the data, the 10 sampling sites for which only one measurement could be made were also used in the further data analysis described below.

The results for the 38 sampling sites are presented in Table 1 and Figure 9. Hydraulic conductivity is highly variable within, as well as between, particular types of superficial deposits from different sample locations reflecting the heterogeneity of these types of materials. Glacial tills had the lowest hydraulic conductivity with a median of $0.027 \mathrm{~m} / \mathrm{d}$, but a range of $<0.001 \mathrm{~m} / \mathrm{d}$ to approximately 1 $\mathrm{m} / \mathrm{d}$. Glacial fluvial deposits, (comprising both fluviatile and lacustrine deposits) had a much higher hydraulic conductivity with a median of $2.5 \mathrm{~m} / \mathrm{d}$, but again a wide range, $<0.1$ to $>40 \mathrm{~m} / \mathrm{d}$. The raised marine deposits showed fairly consistent hydraulic conductivity with median $1.7 \mathrm{~m} / \mathrm{d}$ and interquartile range of $0.9-3 \mathrm{~m} / \mathrm{d}$. Raised Marine deposits in this area are variable in composition and include sands and gravels with relatively high permeability, and the Ardersier Silt Formation which varies in composition from sands to silts. Two sites were in the raised marine Ardersier Silt Formation where it is predominantly silt and these had lower permeability than other sites in Raised Marine deposits. There were few sites in blown sand and glacial moraines. The three available blown sand results were consistent and varied from 4.5 to $9.5 \mathrm{~m} / \mathrm{d}$ reflecting the uniform nature of the material. The three sites testing glacial moraine deposits showed variable permeability 0.15 to > $40 \mathrm{~m} / \mathrm{d}$, and one site had the highest permeability recorded in Morayshire, exceeding the measuring capacity of the Guelph permeameter.

\subsection{Engineering data}

Summary graphs displaying particle size distribution analysis envelopes for each superficial deposit are presented in Figure 10. The $d_{10}, d_{60}$ and sample descriptions are given in Table 1 . The graphs demonstrate a consistency of particle size distribution in the glacial tills, glacial moraine and blown sand; however, there is greater variability in the particle size distribution of the glaciofluvial and the 
raised marine deposits. Moraine and blown sand are coarse deposits with no significant silt or clay components. Raised marine, glaciofluvial and glacial till are mixed fine and coarse deposits with significant proportions of silt and clay.

The soil state descriptions (SSD) of the superficial deposits described at each section are given in Table 1. They display a high degree of variability both between superficial deposit types and, in many cases, within a single superficial deposit category. A comparison of SSD indicates: glacial till to be highly variable but generally denser than other deposits; raised marine and glaciofluvial deposits have moderate SSD (with greater intra-deposit variability than glaciofluvial deposits). Blown sand and moraines have the lowest SSD and appear to have less intra deposit variability, although this could be due to the low sample number.

The dynamic cone resistance values are shown in Table 1 . There is high variability within each superficial deposit type, with the exception of blown sand deposits. In general, till deposits have the highest resistance, followed by glaciofluvial, raised marine, moraine and then finally blown sand deposits.

\subsection{Multiple Linear Regression}

The engineering and hydraulic conductivity data were analysed together using multiple linear regression (MLR) and Pearson correlation tests. Since particle size and hydraulic conductivity are both logarithmically distributed, they were log transformed before analysis. There were 27 sites which had sufficient data to be included in the analysis (Table 1). Table 2 shows the results of the Pearson correlation tests. All parameters, (except $d_{60}$ ) were significantly correlated with hydraulic conductivity. Unsurprisingly there is a high degree of correlation between many of the input parameters, particularly $d_{10}, d_{15}$ and $d_{30}$. 
323 The results of stepwise multiple linear regression for hydraulic conductivity, particle size and cone

324 resistance $(\mathrm{CR})$ are shown in Table 3. The analysis indicates that, for this dataset, cone resistance and $\log d_{10}$ are the only independent predictors of $\log \mathrm{K}$. The relationship for the 27 sites is described as:

Where $D_{10}$ is in $\mathrm{mm}, \mathrm{CR}$ in $\mathrm{MPa}$ and $\mathrm{K}$ in $\mathrm{m} / \mathrm{d}$. The statistical relationship is strong, with $\mathrm{R}^{2}=0.80$ when adjusted for the size of the dataset (Figure 11). Independently, $\log \mathrm{d}_{10}$ and CR predict log K with an $\mathrm{R}^{2}$ of 0.6 and 0.35 respectively. Using soil state description, rather than CR allows a slightly larger dataset of 34 for the analysis. A similar relationship is given : with a similar strength of correlation as for Cone Resistance $\left(R^{2}=0.78\right)$. Figure 12 illustrates how field descriptions of density together with D10 relate to hydraulic conductivity.

The proportion of each fraction, (clay, silt, sand, gravel and cobbles) was also calculated for each sample, and is reported in Table 1 in the material description. Figure 13 demonstrates an overall relationship between the particle size of the largest fraction and hydraulic conductivity, but its overall predictive power is weak, as demonstrated by the 4 orders of magnitude between $10^{\text {th }}$ and $90^{\text {th }}$ percentile for sand, and the weak correlation $\left(R^{2}=0.16\right)$.

\section{Discussion} glaciated catchments of NW Europe, has provided useful information on the dominant factors controlling permeability across the different deposits, and therefore which properties should be 
measured to help characterise hydraulic conductivity. In addition, the methodologies developed within this study have proved an effective way of characterising permeability in a complex catchment: the integrated geological, hydrogeological and engineering approach; and the field methods for measuring in-situ hydraulic conductivity.

The smallest $10 \%$ of particle sizes within the deposit and the relative density of the material together explain much of the variance in hydraulic conductivity for this heterogeneous catchment. Therefore, modified Hazen formulae, which account for relative density as well as $d_{10}$, are likely to be the best method for estimating permeability in these glaciated environments. This is probably due to the range of deposits present, and also to the large variability in the relative density of materials formed within a glaciated environment, where over consolidated glacial tills co-exist next to loose glacial moraines, or modern alluvium. Additional information on the particle size distribution such as those found useful by Alyamani and Şen (1993), were found not to help predict hydraulic conductivity. Our results are consistent with previous studies which highlight the importance of $d_{10}$ in grain size analysis to determine hydraulic conductivity (e.g. Hazen, 1892; Vuković and Soro, 1992; Odong, 2007) and the effect of varying degrees of compaction on hydraulic conductivity (e.g. Watabe et al., 2000; Lu, 2007). These two parameters appear to be the dominant controls on permeability when considering a wide range of different and heterogeneous superficial deposits. The relationship remains strong across the range of materials tested and is therefore useful for this heterogeneous environment. However, for more detailed work in one particular type of material a specific relationship may give more accurate results (e.g. Vinken and Deitrich 2011).

The size of the largest fraction had little predictive power. Therefore, using the bulk descriptors SAND, SILT, or GRAVEL, to help classify the permeability is of limited use. This was also observed in a study by Fogg et al. (1998) who found only a weak correlation between these sorts of bulk 
descriptors and hydraulic conductivity. Particular attention must therefore be given to the presence of silt or clay, and the degree of consolidation of the material. For this reason, where detailed information is not available for a catchment, building a conceptual understanding of the superficial geology, and the palaeo-environment and nature of deposition, can help to generate more information on the likely presence of fines and the degree of compaction (see Griffiths et al., 2011). The influence of the finest $10 \%$ of the material also has relevance for sampling. Drillers logs, and samples taken from the drilling and installation of piezometers, often do not record much of the finest fraction. The fines are held in suspension, or washed away by the drilling process. Therefore samples are best taken from outcrop, or from cores.

The methodology developed to measure hydraulic conductivity of the superficial deposits proved to be robust and relatively rapid to undertake. Targeting measurements to distinct geological outcrops identified by a Quaternary geologist ensured that heterogeneity of the catchment could be confidently reflected in the sampling. Also the repeated Guelph permeameter measurements gave reassuringly similar results at each outcrop $\left(R^{2}=0.9\right)$ and could be undertaken rapidly. Therefore, despite the robust relationship between $d_{10}$, relative density and hydraulic conductivity, it may be more effective to carry out repeated Guelph permeameter measurements at characteristic outcrops than gathering surrogate information and estimating permeability.

The use of soil state descriptors proved reliable, and as significant a predictor when correlated with $\mathrm{d}_{10}$ as cone resistance (Table 2). Therefore, given the difficulties in making in situ measurements of cone resistance, and the wide availability of soil state descriptions in borehole and trial pit logs, observations made in accordance with BS5930:1999 can be used as an adequate substitute for the measurement of relative density.

The wide range and heterogeneous nature of the deposits tested suggests that our findings may be fairly widely applicable in superficial deposits. However it would be useful to obtain more data in 
395

blown sand and glacial moraine deposits and other deposit types that were not tested (e.g. fluvial

396 deposits).

397 
398

399

400

401

402

403

404

405

406

407

408

409

410

411

412

413

414

415

416

417

418

419

420

\section{Conclusions}

This study has investigated the hydraulic conductivity of superficial deposits in a heterogeneous catchment in northern Scotland, typical of many catchments subjected to past glaciations in North West Europe. In total, 38 different deposits were sampled at 25 sections. The deposits comprised: glacial tills and moraines; glaciofluvial and glaciolacustrine deposits; raised marine deposits; and blown sand. Hydraulic conductivity measurements were made using repeated Guelph Permeameter measurements, cone resistance was measured in situ with a Panda dynamic cone penetrometer (to give an indication of relative density); material descriptions were made in accordance with BS5930:1999; and disturbed samples were taken for particle size analysis. The following conclusions can be drawn:

1. In situ measurements of hydraulic conductivity made with a Guelph permeameter at deposit outcrops proved highly repeatable $\left(R^{2}=0.9\right)$.

2. Hydraulic conductivity $(\mathrm{K})$ ranged from $0.001 \mathrm{~m} / \mathrm{d}$ to $>40 \mathrm{~m} / \mathrm{d}$; glacial till had the lowest $\mathrm{K}$ (median $0.027 \mathrm{~m} / \mathrm{d}$ ) and glacial moraine the highest $\mathrm{K}$ (median $30 \mathrm{~m} / \mathrm{d}$ ).

3. The results of stepwise multiple linear regression for hydraulic conductivity, particle size and cone resistance indicate that, for this dataset, cone resistance and log $d_{10}$ are the only independent predictors of $\log K\left[\log K=0.97 \log \left(d_{10}\right)+(2-0.11 C R)\right]$, where $d_{10}$ is in $m m, C R$ in $\mathrm{MPa}$ and $\mathrm{K}$ in $\mathrm{m} / \mathrm{d}$. The statistical relationship is strong, with $\mathrm{R}^{2}=0.80$ when adjusted for the size of the dataset.

4. Using soil state material descriptions made in accordance with BS5930:1999 instead of the cone resistance to give an indication of relative density gave a similar relationship and strength of correlation $\left(R^{2}=0.78\right)$. Therefore high quality soil state descriptions are a good surrogate for cone resistance measurements. 
421 5. The size of the largest fraction had little predictive power. Therefore, using the bulk descriptors SAND, SILT, or GRAVEL, to help classify the permeability of unconsolidated heterogeneous sediments is of only limited use.

424 6. In situ Guelph permeameter measurements at outcrops with careful geological characterisation provide a good method of determining the permeability characteristics of superficial deposits where large-scale permeability testing is not feasible.

With the growing recognition of the importance of the hydraulic conductivity of superficial deposits to many aspects of catchment hydrology and hydrogeology, robust methods of characterising hydraulic conductivity will become increasingly important. The methodologies and relationships developed within this paper should help to inform future studies of catchment permeability.

\section{Acknowledgements}

The authors thank Helen Bonsor, David Entwhistle and David Boon for assistance with fieldwork. 


\section{References}

439 Alyamani, M.S., Şen, Z., 1993. Determination of Hydraulic Conductivity from complete grain size 440 distribution curves. Ground Water, 31, 551-555.

441 Amoozegar, A., 1988. A compact constant-head permeameter for measuring saturated hydraulic 442 conductivity of the vadose zone. Soil Science Society of America Journal, 53, 1356-1361.

443 Angulo-Jaramillo, R., Vandervaere, J.P., Roulier, S., Thony, J.L., Gadet, J.P., Vauclin, M., 2000. Field 444 measurements of soil surface hydraulic properties by disc and ring infiltrometers. A review and 445 recent developments. Soil and Tillage Research, 55, 10-29.

Bagarello, V., 1997. Influence of well preparation on field saturated hydraulic conductivity measured 447 with the Guelph permeameter. Geoderma, 80, 169-180,

British Standards Institution, 1990. BS1377 Part 2.

British Standards Institution, 1999a. BS 5930 Code of practice for site investigations. amendment 1.

Bruce, B.W., McMahon, P.B., 1996. Shallow ground-water quality beneath a major urban center:

Denver, Colorado, USA. Journal of Hydrology 186, 129-151. 

$42,459-464$.

Cuthbert, M.O., Mackay, R., Tellam, J.H., and Barker, R.D., 2009. The use of electrical resistivity tomography in deriving local-scale models of recharge through superficial deposits. Quarterly Journal of Engineering Geology and Hydrogeology 42, 199-209.

Daniel, D.E., 1989. In situ hydraulic conductivity tests for compacted clay. Journal of Geotechnical laboratory testing. unsaturated zone using improved well analyses. Groundwater Monitoring and Remediation, 9 (3), 184-193.

Fogg, G.E., Noyes, C.D., Carle, S.F., 1998. Geologically based model of heterogeneous hydraulic conductivity in an alluvial setting. Hydrogeology Journal, 6, 131-143. Hydrology, 21, 119-132. predict preferred flow paths in a heterogeneous aquifer. Journal of Contaminant Hydrology, 82, 7595. 

assessment using overlay and index methods. Environmental Geology, 39, 549-559.

482

Griffiths, K.J., MacDonald, A.M., Robins, N.S., Merritt, J., Booth, S.J., Johnson, D., and McConvey, P.J., 2011. Improving the characterisation of Quaternary deposits for groundwater vulnerability assessments using maps of recharge and attenuation potential. Quarterly Journal of Engineering Geology and Hydrogeology, 43, 49-61.

Hazen, A. 1892. Some Physical Properties of Sands and Gravels, with Special Reference to their Use in Filtration. 24th Annual Report, Massachusetts State Board of Health, Pub.Doc. No.34, 539-556.

Hendry, M.J., 1982. Hydraulic Conductivity of a glacial till in Alberta. Ground Water, 20, 162-169.

Hubbard, B., Maltman, A., 2000. Laboratory investigations of the strength, static hydraulic conductivity and dynamic hydraulic conductivity of glacial sediments, In: Maltman, A.J., Hubbard, B., Hambrey, M.J. (Eds.), Deformation of Glacial Materials. Geological Society London Special Publications, 176, 231-242.

Jones, L., Lemar, T., Tsai, C., 1992. Results of two pumping tests in Wisconsin age weathered till in lowa. Ground Water, 20, 529-538.

Jones, L., 1993. A comparison of pumping and slug tests for estimating the hydraulic conductivity of unweathered Wisconsin age till in lowa. Ground Water, 31, 896-904.

Keller, C.K., Van der Kamp, G., and Cherry, J.A., 1988. Hydrogeology of two Saskatchewan tills, I. fractures, bulk permeability, and spatial variability of downward flow. Journal of Hydrology, 101, 97121.

Keller, C.K., Van der Kamp, G., Cherry, J.A., 1989. A multiscale study of the permeability of a thick clayey till. Water Resources Research, 25, 2299-2317. 
502

503

504

505

506

507

508

509

510

511

512

513

514

515

516

517

518

519

520

521

522

Kolterman, C.E., Gorelick, S.M., 1995. Fractional Packing model for hydraulic conductivity derived from sediment mixtures. Water Resources Research, 31, 3283-3297.

Kozeny, J. 1927. Uber Kapillare Leitung Des Wassers in Boden. Sitzungsber Akad. Wiss. Wien Math. Naturwiss.Kl., Abt.2a, 136, 271-306.

Lake, I.R., Lovett, A.A., Hiscock, K.M., Betson, M., Foley, A., Sünnenberg, G., Evers, S., Fletcher, S., 2003. Evaluating factors influencing groundwater vulnerability to nitrate pollution: developing the potential of GIS. Journal of Environmental Management, 68, 315-328.

Langton, D.D., 1999. The Panda lightweight penetrometer for soil investigation and monitoring material compaction. Ground Engineering, September 1999, 33 - 37.

Lloyd, J. W., Harker, D. Baxendale, R. A., 1981. Recharge mechanisms and groundwater flow in the Chalk and drift deposits of southern East Anglia. Quarterly Journal of Engineering Geology, 14, 8796.

MacDonald, A.M., Robins, N.S., Ball, D.F., Ó Dochartaigh, B.E., 2005. An overview of groundwater in Scotland. Scottish Journal of Geology, 41, 3-11.

Macdonald, D.M.J., Bloomfield, J.P., Hughes, A.G., MacDonald, A.M., Adams, B., McKenzie, A.A., 2008. Improving the understanding of the risk from groundwater flooding in the UK. In: FLOODrisk 2008, CRC Press, Leiden. The Netherlands.

Maupin, M.A., Barber, N.L., 2005. Estimated withdrawals from principal aquifers in the United States, 2000. U.S. Geological Survey Circular 1279, 46 pp.

McCloskey, T.F., Finnemore, E.J., 1996. Estimating Hydraulic Conductivities in an Alluvial Basin from Sediment Facies Models. Ground Water, 34, 1024-1032. 
McEwen, L.J., Werritty, A., 2007. 'The Muckle Spate of 1829': the physical and societal impact of a catastrophic flood on the River Findhorn, Scottish Highlands. Transactions of the Institute of British Geographers, 32, 66-89.

McKay, L.D., Cherry, J.A., Gillham, R.W., 1993. Field experiments in a fractured clay till 1. Hydraulic conductivity and fracture aperture. Water Resources Research, 29, 1149-1162.

McMillan, A.A., Heathcote, J.A., Klinck, B.A., Shepley, M.G., Jackson, C.P., Degnan, P.J., 2000. Hydrogeological characterization of the onshore Quaternary sediments at Sellafield using the concept of domains. Quarterly Journal of Engineering Geology and Hydrogeology, 33, 301-323.

Meinken W., Stobar, I., 2003. Permeability distribution in the Quaternary of the Upper Rhine glaciofluvial aquifer. Terra Nova, 9, 113-116.

Melville, J.G., Molz, F.J., Guven, O., Widdowson, M.A., 1991. Multilevel slug tests with comparisons to tracer data. Ground Water, 29, 897-907.

Milham, N.P., Howes, B.L., 1995. A comparison of methods to determine K in shallow coastal aquifer. Ground Water, 33, 49-57.

Misstear, B.D.R., Brown, L. and Johnston, P. 2009. Estimation of groundwater recharge in a major sand and gravel aquifer in Ireland using multiple approaches. Hydrogeology Journal, 17, 693- 706.

Mohanty, B.P., Kanwar, R.S., Everts, C.J., 1994. Comparison of saturated hydraulic conductivity measurements for a glacial-till soil. Soil Science Society of America Journal, 58, 672-677.

Mondol, N.H., Bjorlykke K., Jahren J. and Hoeg K., 2007. Experimental mechanical compaction of clay mineral aggregates - Changes in physical properties of mudstones during burial. Marine and Petroleum Geology, 24, 289-311. 
Morrice, J.A. , Valett, H.M, Dahm,C.N., Campana, M.E., 1997. Alluvial characteristics, groundwater-

545

546

547

548

549

550

551

552

553

554

555

556

557

558

559

560

561

562

563

564

565

surface water exchange and hydrological retention in headwater streams. Hydrological Processes, 11, 253-267.

Neuzil, C.E., 1994. How permeable are clays and shales? Water Resources Research, 30, 145-150.

Nilsson, B., Sidle, R.C., Klint, K.E., Bøgglid, C.E., and Broholm, K., 2001. Mass transport and scaledependent hydraulic tests in a heterogeneous glacial till-sandy aquifer system. Journal of Hydrology 243, 162-179.

Perroux, K.M., White, I., 1988. Designs for disc permeameters. Soil Science Society of America Journal, 52, 1205-1215.

Ó Dochartaigh, B.E., Ball, D.F., MacDonald, A.M., Lilly, A., Fitzsimons, V. del Rio, M., Auton, C., 2005 Mapping groundwater vulnerability in Scotland: a new approach for the Water Framework Directive. Scottish Journal of Geology, 41, 21-30.

Ó Dochartaigh, B.E., Smedley, P.L., MacDonald, A.M., Darling, W.G. 2010 Baseline Scotland: groundwater chemistry of the Old Red Sandstone aquifers of the Moray Firth area. Nottingham, UK, British Geological Survey (OR/10/031), 86pp.

Odong, J., 2007. Evaluation of empirical formulae for determination of hydraulic conductivity based on grain size analysis. Journal of American Science, 3, 54-60.

Renard, P., 2005. The future of hydraulic tests, Hydrogeology Journal, 13, 259-262.

Reynolds, W.D., Elrick, D.E., 1985. In situ measurement of filed saturated hydraulic conductivity. Sorptivity, and the alpha parameter using the Guelph permeameter. Soil Science, 140 292-302.

Reynolds, W.D., Vieira, S.R., Topp, G.C., 1992. An assessment of the single-head analysis for the constant head well permeameter. Canadian Journal of Soil Science, 72, 489-501. 
566

567

568

569

570

571

572

573

574

575

576

577

578

579

580

581

582

583

584

585

586

587

Shepherd, R.G., 1989. Correlations of permeability and grain size. Ground Water, 27, 633-638.

Schlichter, C.S., 1899. Theoretical investigation of the motion of ground waters. U.S. Geological Survey 19th Annual Report part 2, pp 295-384.

Schulze-Makuch, D., Carlson, D.A., Cherkauer, D.S., Malik, P., 1999. Scale dependency of hydraulic conductivity in heterogeneous media. Ground Water, 37, 904-919.

Shepherd, R. G., 1989. Correlations of permeability and grain-size. Ground Water, 27, 633-638.

Song J.X., Chen X.H., Cheng C., Wang D.M., Lackey S., Xu Z.X. 2009. Feasibility of grain-size analysis methods for determination of vertical hydraulic conductivity of streambeds. Journal of Hydrology, $375,428-437$.

Soulsby, C., Tetzlaff, D., van den Bedem, N., Malcolm, I.A., Bacon, P.J., Youngson, A.F., 2007. Inferring groundwater influences on surface water in montane catchments from hydrochemical surveys of springs and streamwaters. Journal of Hydrology, 333, 199-213.

Sperry, J.M., Pierce, J.J., 1995. A model for estimating the hydraulic conductivity of granular material based on grain shape, grain size and porosity. Ground Water, 33, 892-898.

Summers, W.K., Weber, P.A., 1984. The relationship of grain size distribution and hydraulic conductivity - an alternate approach. Ground Water, 22, 474-475.

Taylor, K., Wheatcraft, S., Hess, J., Hayworth, J., Molz, F., 1990. Evaluation of methods for determining the vertical distribution of hydraulic conductivity. Ground Water, 28, 88-97.

Vienken, T. And Dietrich, P., 2011. Field methods of determining hydraulic conductivity from grain size data. Journal of Hydrology, 400, 58-71.

Vuković, M., Soro, A., 1992. Determination of Hydraulic Conductivity of porous media from grain size composition. Water Resources Publication LLC, Colorado. 83pp. 
588 Watabe, Y., Leroueil, S., Le Bihan, J.P., 2000. Influence of compaction conditions on pore-size

589 distribution and saturated hydraulic conductivity of a glacial till. Canadian Geotechnical Journal, 37,

$590 \quad 1184-1194$.

591

592 
Figure 1: Simplified superficial geological map of the study area.

Figure 2: Schematic cross section across the area illustrating the general succession of deposits.

Figure 3: Guelph Permeameter measuring hydraulic conductivity of the grey coloured Ardersier Silts at Cloddymoss (locality 20, Figure 1) with ledges below excavated into the underlying orange coloured till.

Figure 4: Ledge and hole excavated into raised marine sands.

Figure 5: Panda Penetrometer test undertaken in till

Figure 6: Results of cone resistance tests using the Panda2 instrument at the Grangehall Ditch glaciofluvial site (site 11 on Figure 1) and the Ardersier Silt Race Track site (Site 15 on Figure 1).

604

Figure 7: Example plots of water depth in the Guelph Permeameter reservoir with time used to

605 determine the steady intake rate of water, with the resulting hydraulic conductivity values (K).

606 Repeated measurements (A and B) within the same deposit at the same site show largely consistent results.

Figure 8: Comparison of duplicate hydraulic conductivity measurements ( $\mathrm{A}$ and $\mathrm{B}$ ) taken in the same material at the same section, generally sampled within $5 \mathrm{~m}$ of each other.

Figure 9: Box plot of hydraulic conductivity (one value per site) for superficial deposits in Morayshire.

611 The number of sites where hydraulic conductivity was measured is shown in brackets. (Glaciofluvial

612 material includes both fluviatile and lacustrine deposits).

613 Figure 10: Particle Size Distribution envelopes for each superficial deposit type. 
614 Figure 11: Relationship between predicted hydraulic conductivity (using $d_{10}$ and Cone Resistance

615 (CR)) and measured hydraulic conductivity (K) for 27 sites in heterogeneous superficial deposits in 616 Morayshire.

617 Figure 12: Relationship between hydraulic conductivity, $d_{10}$ and soil state descriptor as observed in 618 the field.

619 Figure 13: Box plots of hydraulic conductivity plotted for particle size of the largest fraction in each

620 sample. Note that this has much less predictive power $\left(R^{2}=0.16\right)$ than using $d_{10}$ and $C R\left(R^{2}=0.8\right)$.

621

622 


\begin{tabular}{|c|c|c|c|c|c|c|c|}
\hline $\begin{array}{c}\text { Locality (and site number on } \\
\text { Fig. 1) }\end{array}$ & Lithology & $\begin{array}{c}\text { Strength } \\
\text { description }\end{array}$ & $\begin{array}{c}\text { In situ } \mathrm{k} \\
\text { ( } \mathrm{m} / \mathrm{day})\end{array}$ & $\begin{array}{c}\text { In situ Cone } \\
\text { Resistance (Mpa) }\end{array}$ & $d_{10}$ & $\mathbf{d}_{60}$ & Material Description \\
\hline Rivermeads (1) & Glacial Till & Dense & 0.102 & 6.2 & 0.0060 & 0.5894 & Gravelly (f-c) very silty SAND (f-m) with some COBBLES \\
\hline Rivermeads (1) & Glaciofluvial & Loose & 1.04 & 2.32 & 0.0019 & 0.1700 & Gravelly $(f-m)$ very silty SAND (f-m) \\
\hline Highland Boath (2) & Glacial Moraine & Very Loose & 26.8 & & 0.4104 & 16.8732 & SAND $(\mathrm{f}-\mathrm{c})$ and GRAVEL $(\mathrm{m}-\mathrm{c})$ with some cobbles \\
\hline Riereach Burn Site 1 (3) & Glacial Till & Very Dense & 0.01 & 10.555 & 0.0011 & 0.7693 & Very clayey very gravelly $(\mathrm{f}-\mathrm{c})$ SAND $(\mathrm{f}-\mathrm{c})$ \\
\hline Riereach Burn Site 1 (3) & Glacial Till & Very Dense & 0.051 & 9.52 & 0.0096 & 1.3623 & Silty very gravelly $(\mathrm{f}-\mathrm{c})$ SAND $(\mathrm{f}-\mathrm{c})$ \\
\hline Riereach Burn Sand Pit (4) & Glaciofluvial & Loose & 31.1 & 3.61 & 0.1863 & 0.5880 & $\mathrm{~N} / \mathrm{A}$ \\
\hline Drynachan (5) & Glacial Till & Dense & 1.3 & 6.21 & 0.0186 & 0.3025 & Gravelly $(f-m)$ very silty SAND $(f-m)$ \\
\hline Drynachan (5) & Glacial Till & Dense & 0.054 & 7.52 & & & Gravelly $(\mathrm{f}-\mathrm{m})$ very silty SAND $(\mathrm{f}-\mathrm{m})$ \\
\hline Drynachan (5) & Glacial Till & Very Dense & 0.015 & 12.63 & 0.0106 & 0.3534 & Gravelly $(\mathrm{f}-\mathrm{m})$ very silty SAND $(\mathrm{f}-\mathrm{c})$ \\
\hline Riereach Burn Site 2 (6) & Glacial Till & Dense - Very Dense & 0.12 & 9.99 & 0.0024 & 0.7711 & Very silty very gravelly $(\mathrm{f}-\mathrm{c})$ SAND $(\mathrm{f}-\mathrm{c})$ \\
\hline Dunearn (7) & Glaciolacustrine & Firm & 0.042 & 9.08 & 0.0010 & 0.0083 & Slightly clayey SILT \\
\hline Dunearn (7) & Glaciolacustrine & Loose & 2.51 & & 0.0232 & 0.1383 & Silty SAND (f) \\
\hline Dunearn (7) & Glaciolacustrine & Loose & 30.2 & & 0.2581 & 0.5153 & SAND $(m-c)$ \\
\hline Easterton (8) & Glacial Till & Loose - Med. Dense & 0.151 & 2.84 & 0.0038 & 0.2498 & Gravelly (f-c) very silty SAND ( $\mathrm{f}-\mathrm{m}$ ) with some cobbles \\
\hline Findhorn Raised Marine (9) & Raised Marine & Medium Dense & 3.2 & 12.545 & 0.1759 & 16.6746 & SAND $(f-m)$ and GRAVEL $(m-c)$ \\
\hline Findhorn Raised Marine (9) & Raised Marine & Very Loose & 4.97 & 1.11 & 0.1355 & 0.2045 & SAND (f-m) \\
\hline Chapleton Mountain Bike (10) & Glaciofluvial & Medium Dense & 1.77 & 7.575 & 0.2653 & 11.3743 & Very sandy (f-c) GRAVEL (f-c) with a little cobbles \\
\hline Grange Hall Ditch (11) & Glaciofluvial & Loose & 0.432 & 3.22 & & & Gravelly SAND (not fully recorded) \\
\hline Grange Hall Ditch (11) & Glaciofluvial & Loose & 0.048 & 1.595 & 0.0025 & 0.3045 & Silty gravelly $(\mathrm{f}-\mathrm{c})$ SAND $(\mathrm{f}-\mathrm{m})$ \\
\hline Findhorn Blown Sand (12) & Blown Sand & Very Loose & 8.55 & 0.75 & 0.1339 & 0.2043 & SAND (f-m) \\
\hline Findhorn Blown Sand 2 (13) & Blown Sand & Very Loose & 9.46 & 0.65 & & & SAND (f-m) \\
\hline Ardersier Silt (14) & Raised Marine & Soft - Firm & 0.575 & 2.98 & 0.0015 & 0.0279 & Slightly sandy slightly clayey SILT \\
\hline Ardersier Silt Race Track (15) & Raised Marine & Very Loose & 2.33 & 4.98 & 0.0388 & 0.1780 & Silty SAND (f-m) \\
\hline Dunearn Pit (16) & Glaciofluvial & Loose & 8.06 & 1.48 & 0.1113 & 0.2039 & SAND $(\mathrm{f}-\mathrm{m})$ \\
\hline Dunearn Pit (16) & Glaciofluvial & Dense & 5.53 & $>$ & 0.7146 & 33.7607 & Very sandy (m-c) GRAVEL (f-c) with some cobbles \\
\hline Riereach Road Moraine (17) & Glacial Moraine & Very Loose & $>40$ & 2.6 & 0.6856 & 6.0503 & Very sandy $(\mathrm{m}-\mathrm{c})$ GRAVEL $(\mathrm{f}-\mathrm{c})$ \\
\hline Riereach Road Moraine (17) & Glacial Moraine & Loose - Med. Dense & 0.147 & 13.68 & 0.1175 & 12.1595 & Silty very gravelly (c) SAND (f-c) \\
\hline Culbin Forest (18) & Blown Sand & Very Loose & 4.41 & 0.99 & 0.1491 & 0.2207 & SAND $(f-m)$ \\
\hline Grange Hill (19) & Glacial Till & Dense - Very Dense & 0.027 & 3.33 & 0.0010 & 0.2077 & Gravelly $(\mathrm{f}-\mathrm{m})$ very silty SAND (f-m) \\
\hline Cloddymoss (20) & Glacial Till & Dense & 0.0012 & 9.8 & 0.0019 & 0.2935 & Gravelly $(\mathrm{f}-\mathrm{c})$ very silty SAND $(\mathrm{f}-\mathrm{c})$ \\
\hline Cloddymoss (20) & Raised Marine & Stiff & 0.013 & 2.695 & 0.0010 & 0.0176 & Slightly sandy (f) slightly clayey SILT \\
\hline Cothall $(21)$ & Glaciofluvial & Loose & 4.93 & & 0.1727 & 0.4087 & Slightly gravelly (f) slightly silty SAND $(\mathrm{m})$ \\
\hline Cothall (21) & Glacial Till & Firm - Stiff & 0.006 & 11.87 & 0.0010 & 0.2175 & Slightly gravelly $(\mathrm{f}-\mathrm{m})$ slightly clayey sandy $(\mathrm{f}-\mathrm{c}) \mathrm{SILT}$ \\
\hline Croft Road Wood (22) & Raised Marine & Loose & 1.1 & 3.74 & 0.0289 & 0.1619 & Slightly clayey silty SAND (f-m) \\
\hline Altyre Estate Site No. 3 (23) & Glacial Till & Very Dense & 0.004 & & & & Slightly silty gravelly $(\mathrm{f}-\mathrm{c})$ SAND $(\mathrm{f}-\mathrm{c})$ \\
\hline Altyre Estate Site No. 1 (24) & Glacial Till & Dense & 0.004 & & 0.0051 & 0.5129 & Very silty very gravelly (f-c) SAND (f-m) \\
\hline Wind Farm (25) & Raised Marine & Loose & 2.94 & 1.46 & 0.1365 & 0.2106 & SAND $(f-m)$ \\
\hline Wind Farm (25) & Raised Marine & Loose & 1.04 & & 0.2457 & 22.2066 & Very sandy $(m)$ GRAVEL $(m-c)$ \\
\hline
\end{tabular}


Table 2: Pearson correlation matrix for in situ hydraulic conductivity and engineering parameters for 27 samples in Morayshire

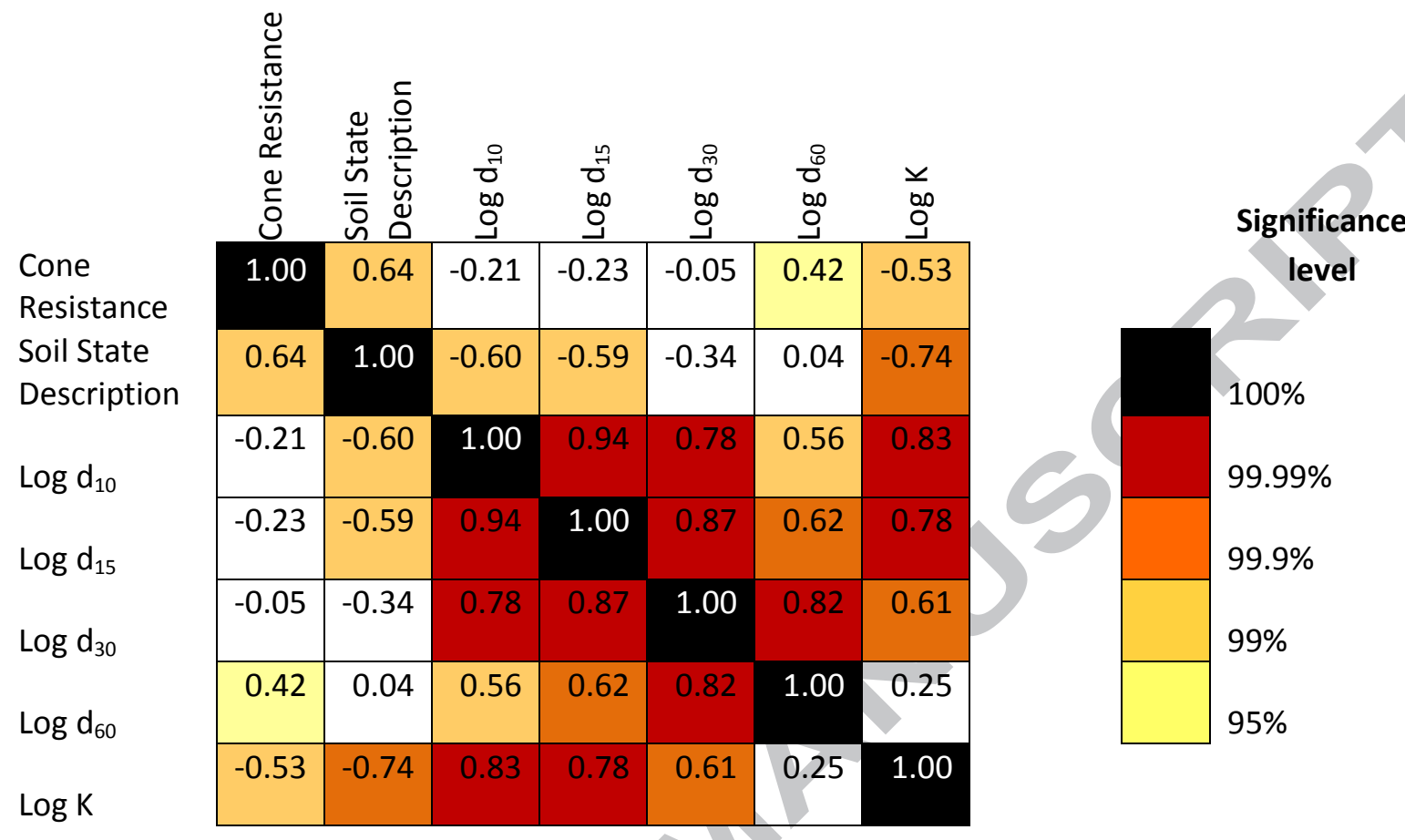

Table 3: $\mathrm{P}$ values for multiple linear regression analysis of the Morayshire dataset for log $\mathrm{K}$ and various material properties. The sign indicates whether the predictor is directly (+) or inversely (-) related.

\begin{tabular}{lcccr}
\hline \multicolumn{1}{c}{ Source } & Value & $\begin{array}{c}\text { Standard } \\
\text { error }\end{array}$ & $\mathrm{t}$ & $\mathrm{Pr}>|\mathrm{t}|$ \\
\hline $\log 10$ & 1.123 & 0.349 & 3.216 & $\mathbf{0 . 0 0 4}$ \\
Cone Res (MPa) & -0.096 & 0.046 & -2.091 & $\mathbf{0 . 0 4 9}$ \\
$\operatorname{logd15}$ & -0.313 & 0.519 & -0.602 & 0.553 \\
$\operatorname{logd30}$ & 0.456 & 0.630 & 0.723 & 0.478 \\
$\operatorname{logd60}$ & -0.235 & 0.430 & -0.547 & 0.590 \\
\hline
\end{tabular}

Bold are those significant at the 95\% level 


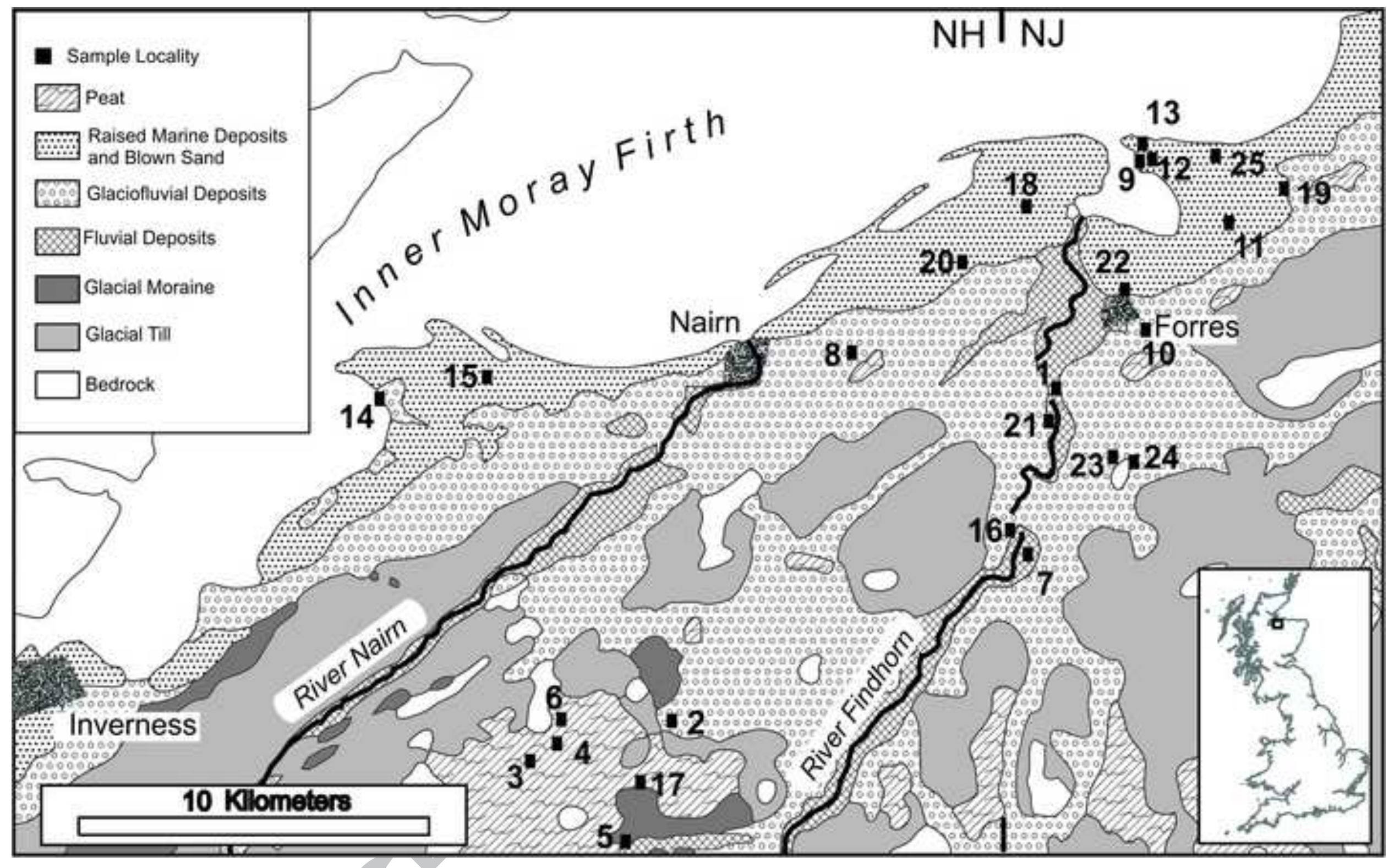




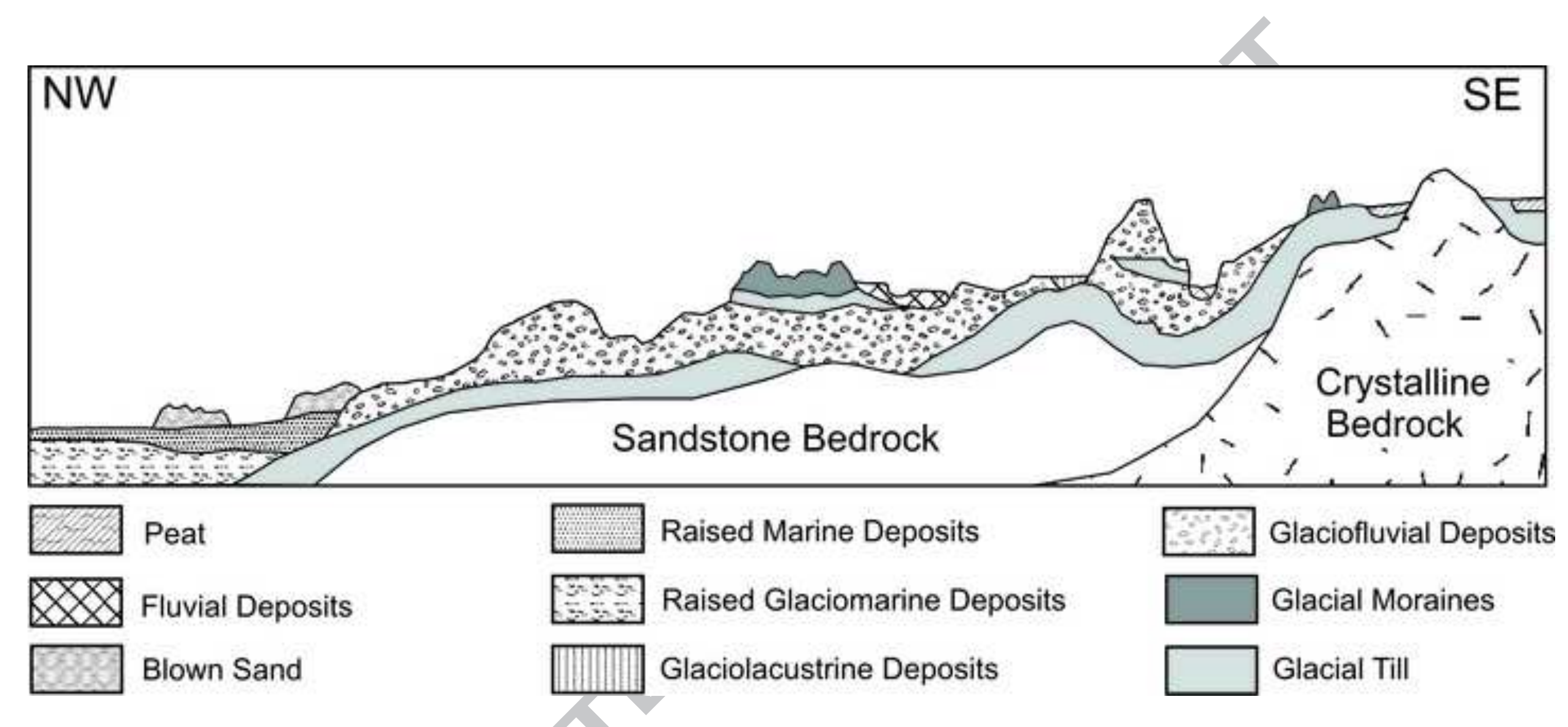




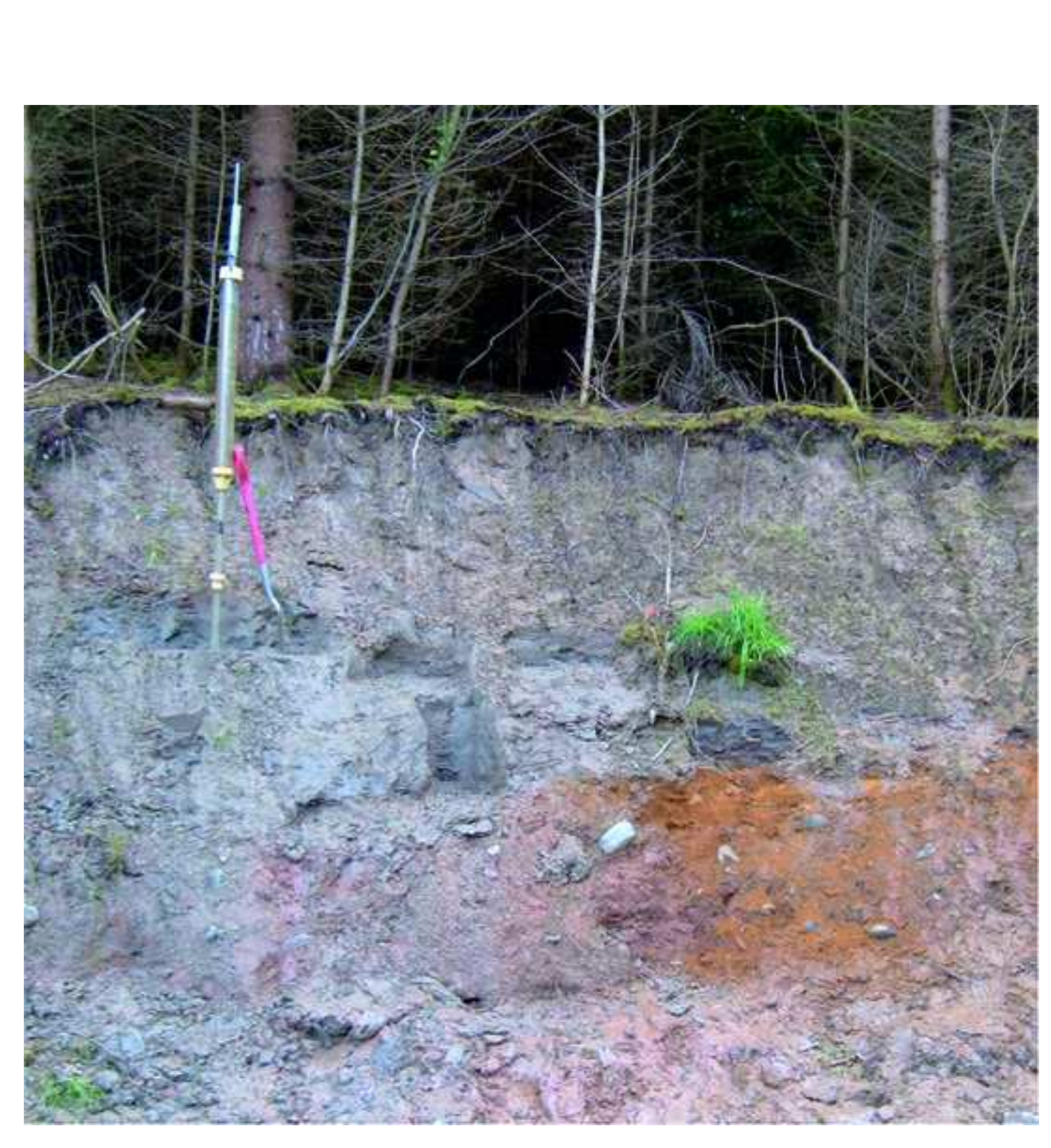

- T. T ACCEPTED MANUSCRIPT 


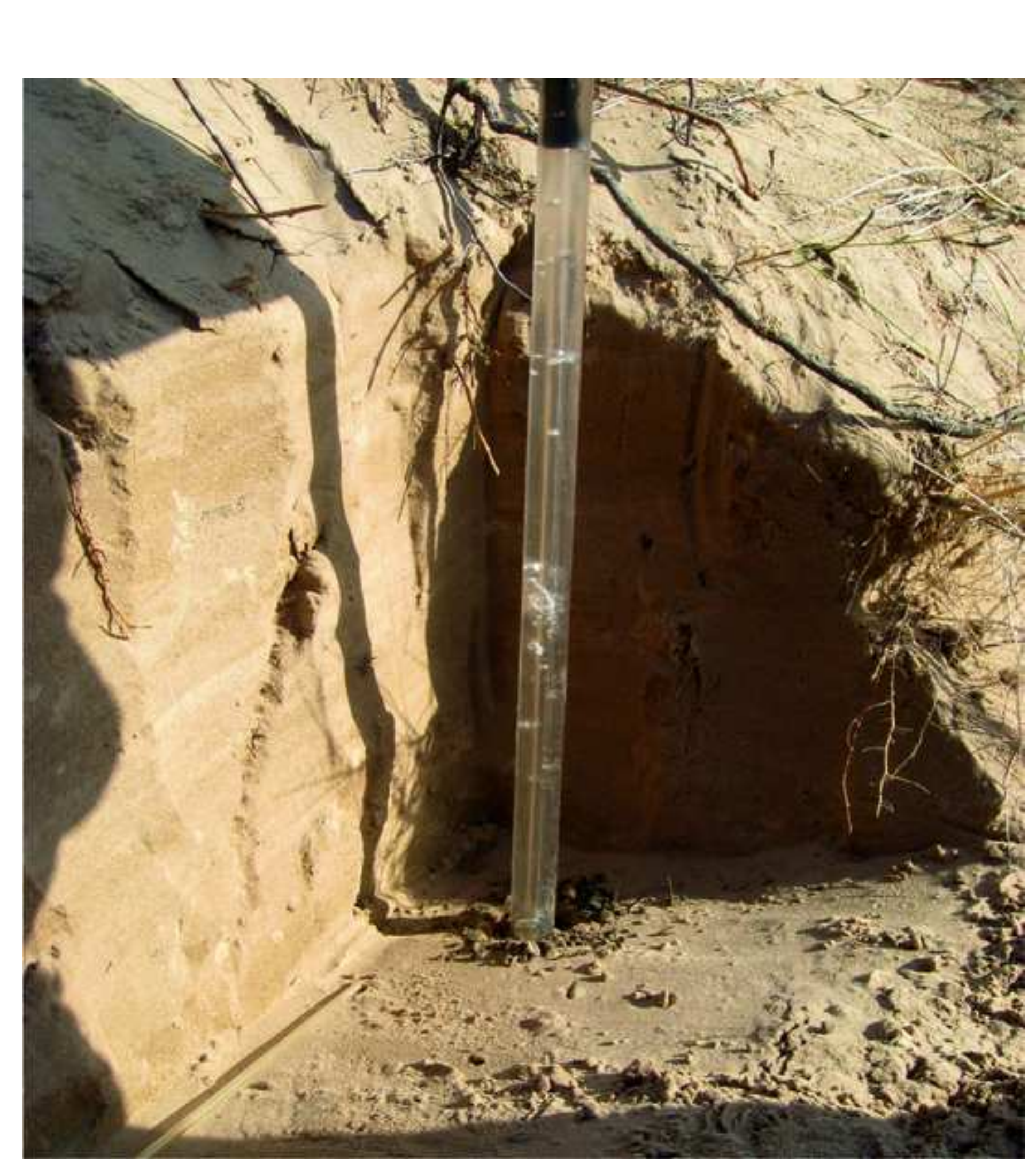




\section{Grangehall Ditch}

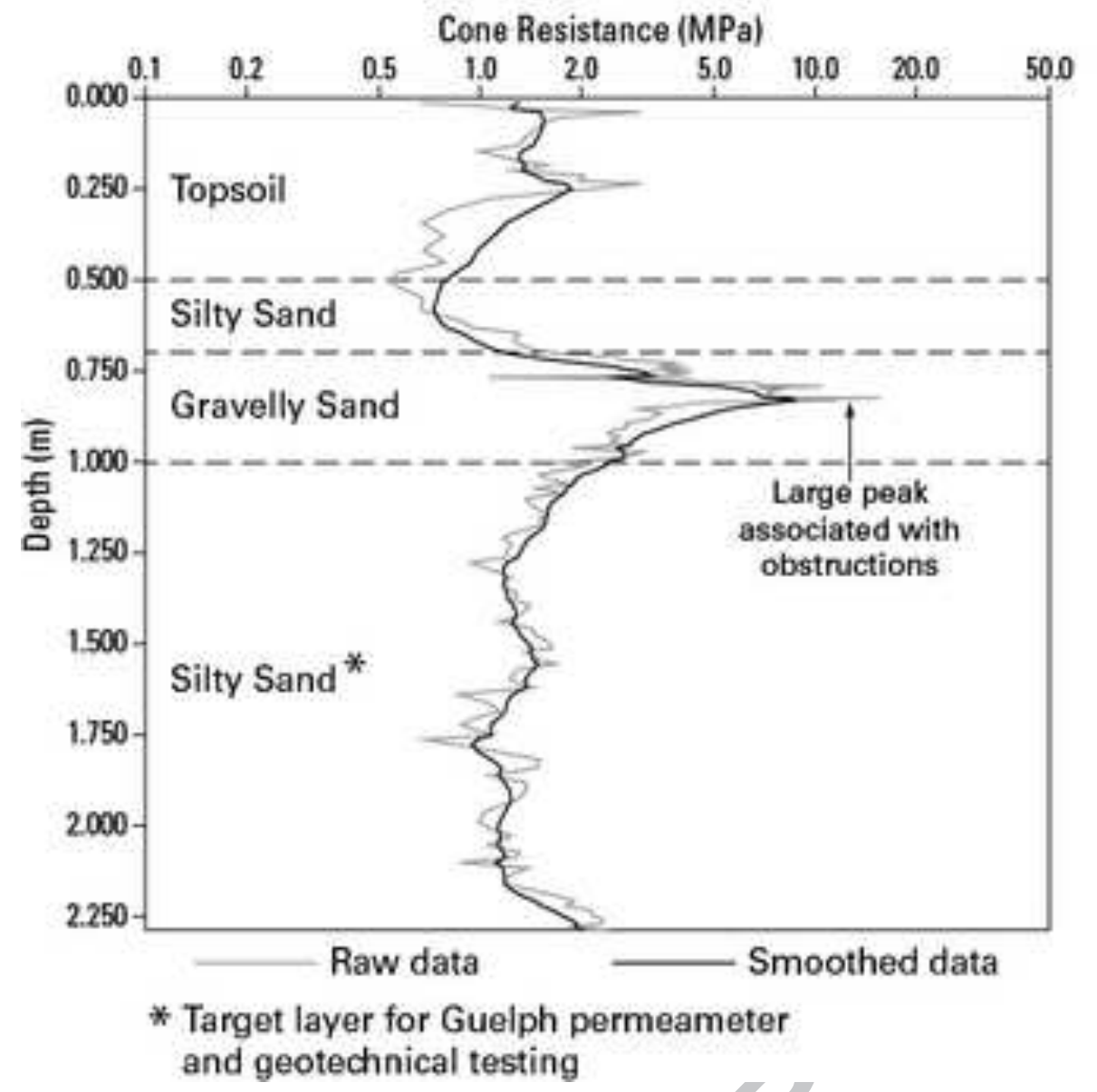

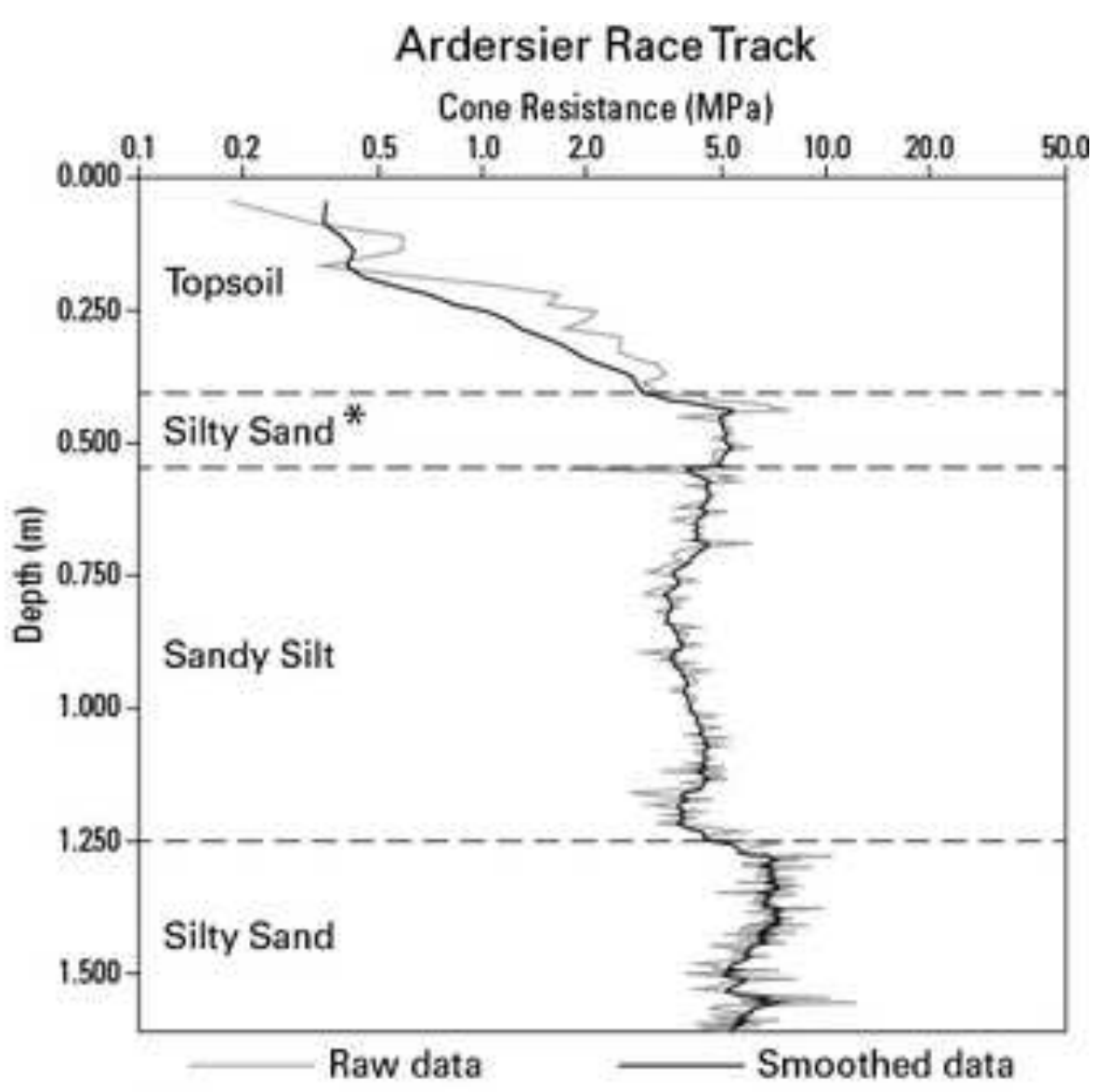

* Target layer for Guelph permeameter and geotechnical testing 
Highland Boath Moraine 1

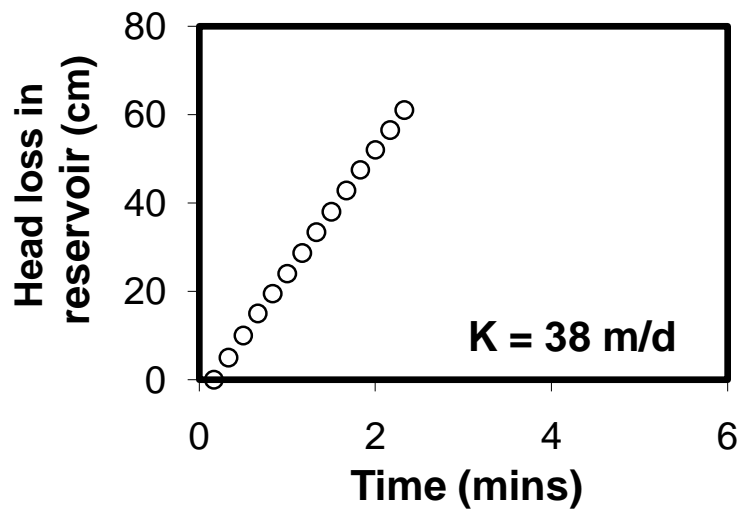

Dunearn Fine-Medium Sand 1

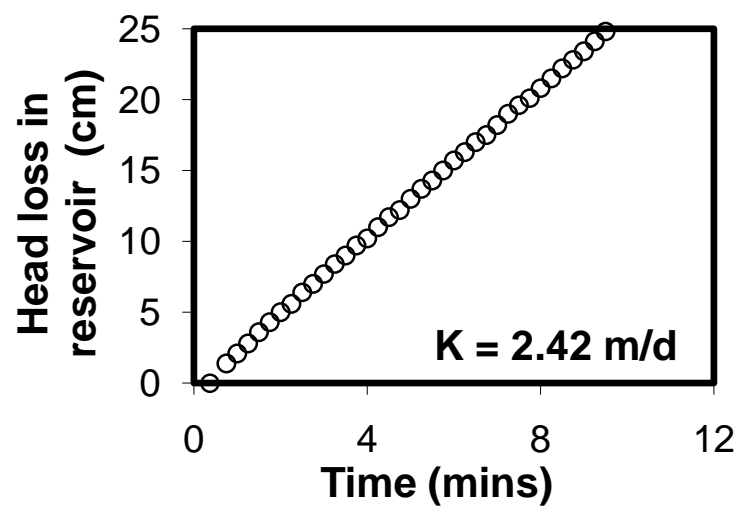

Grange Hill Red Till 1

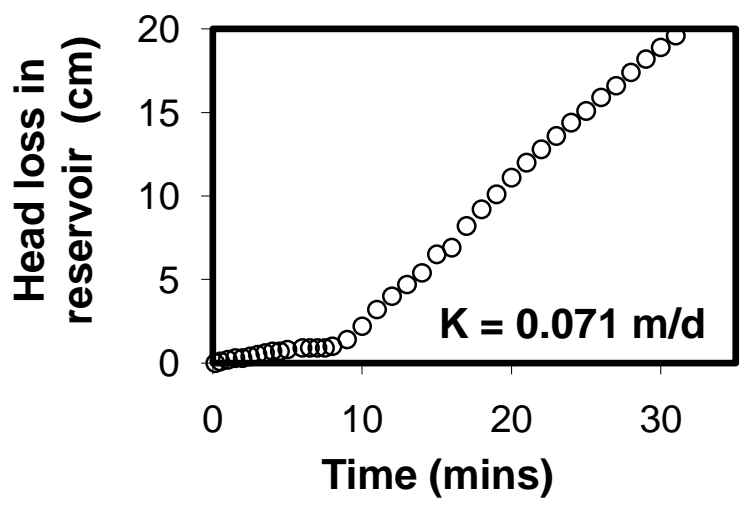

Highland Boath Moraine 2

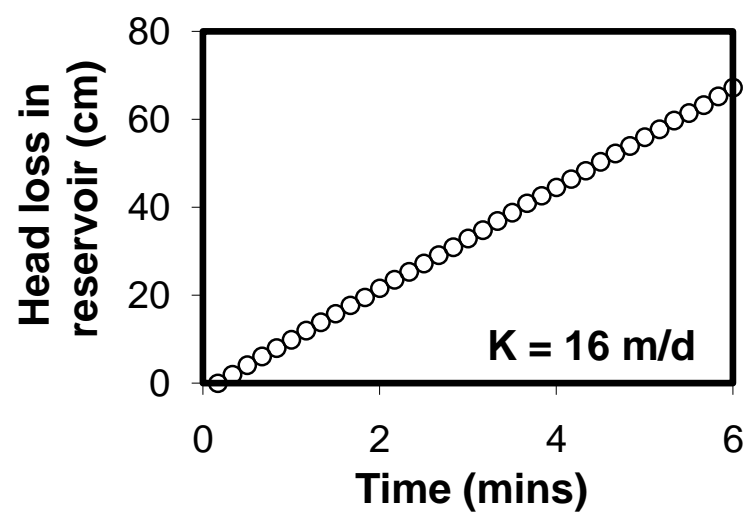

Dunearn Fine-Medium Sand 2

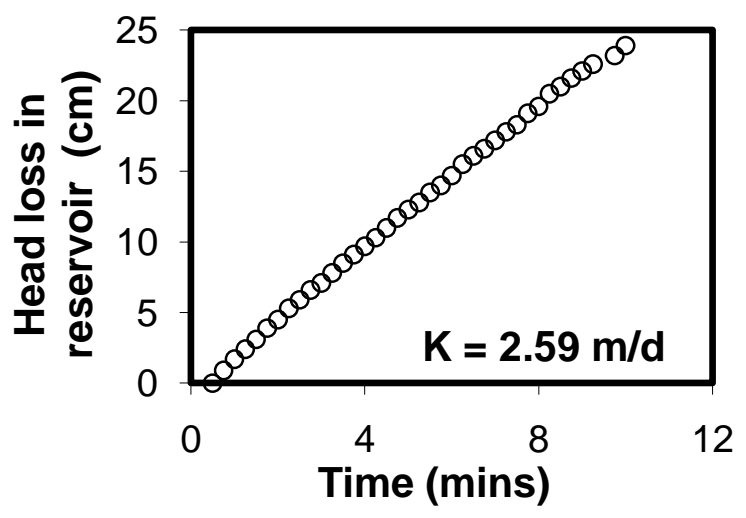

Grange Hill Red Till 2

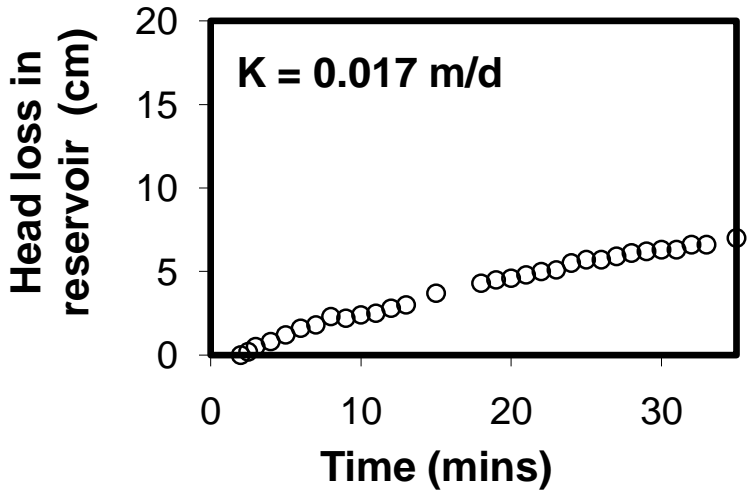




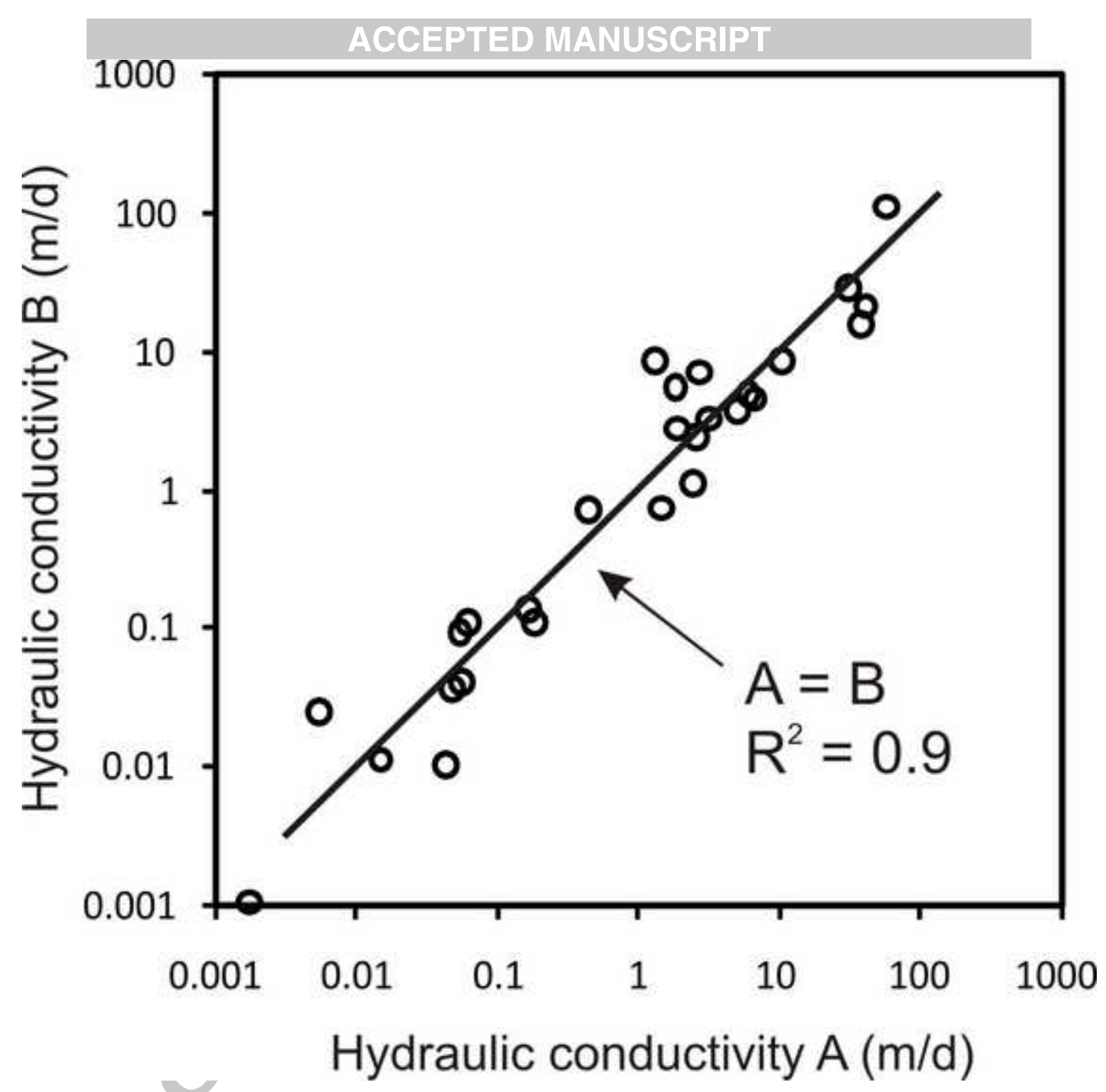




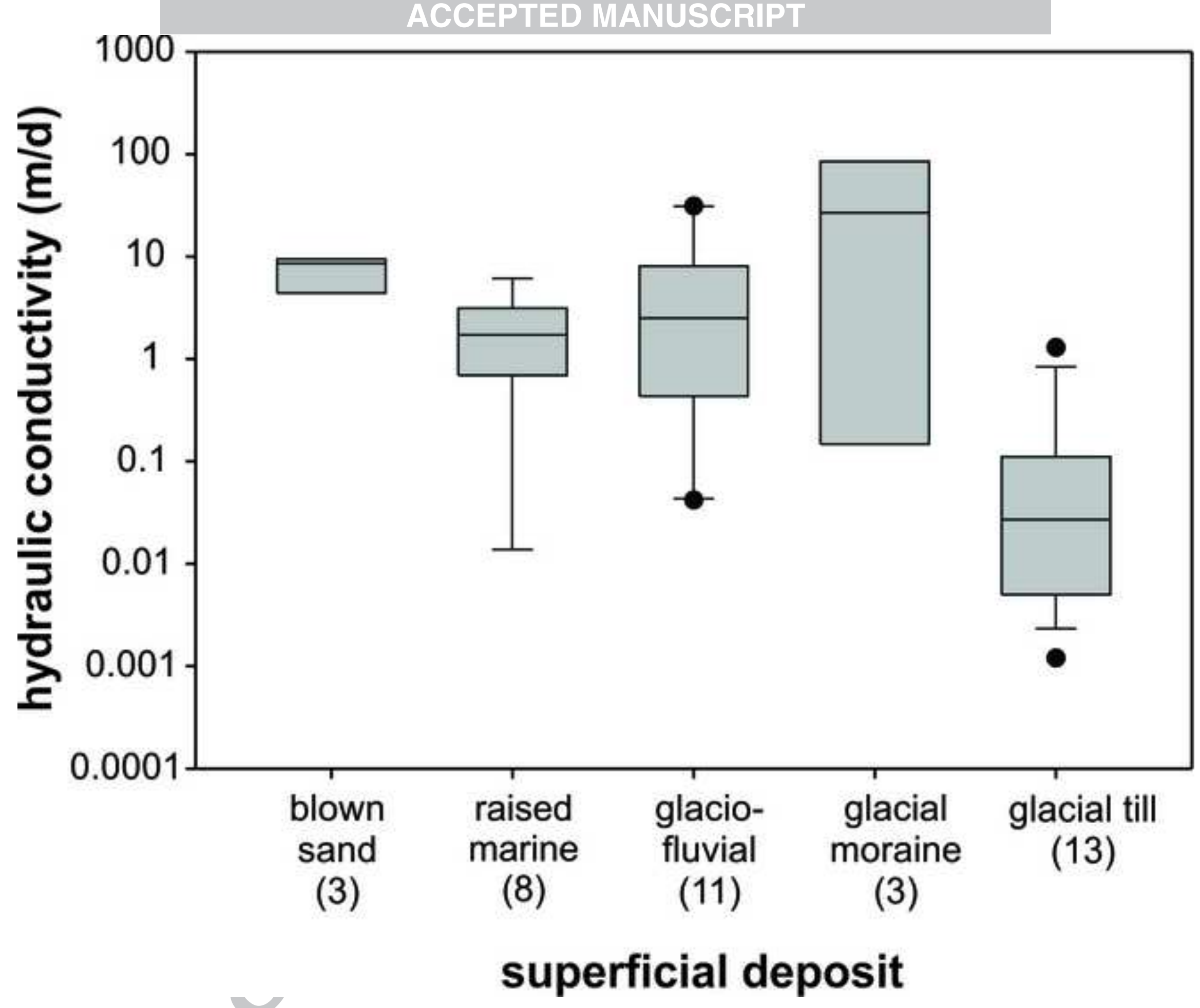



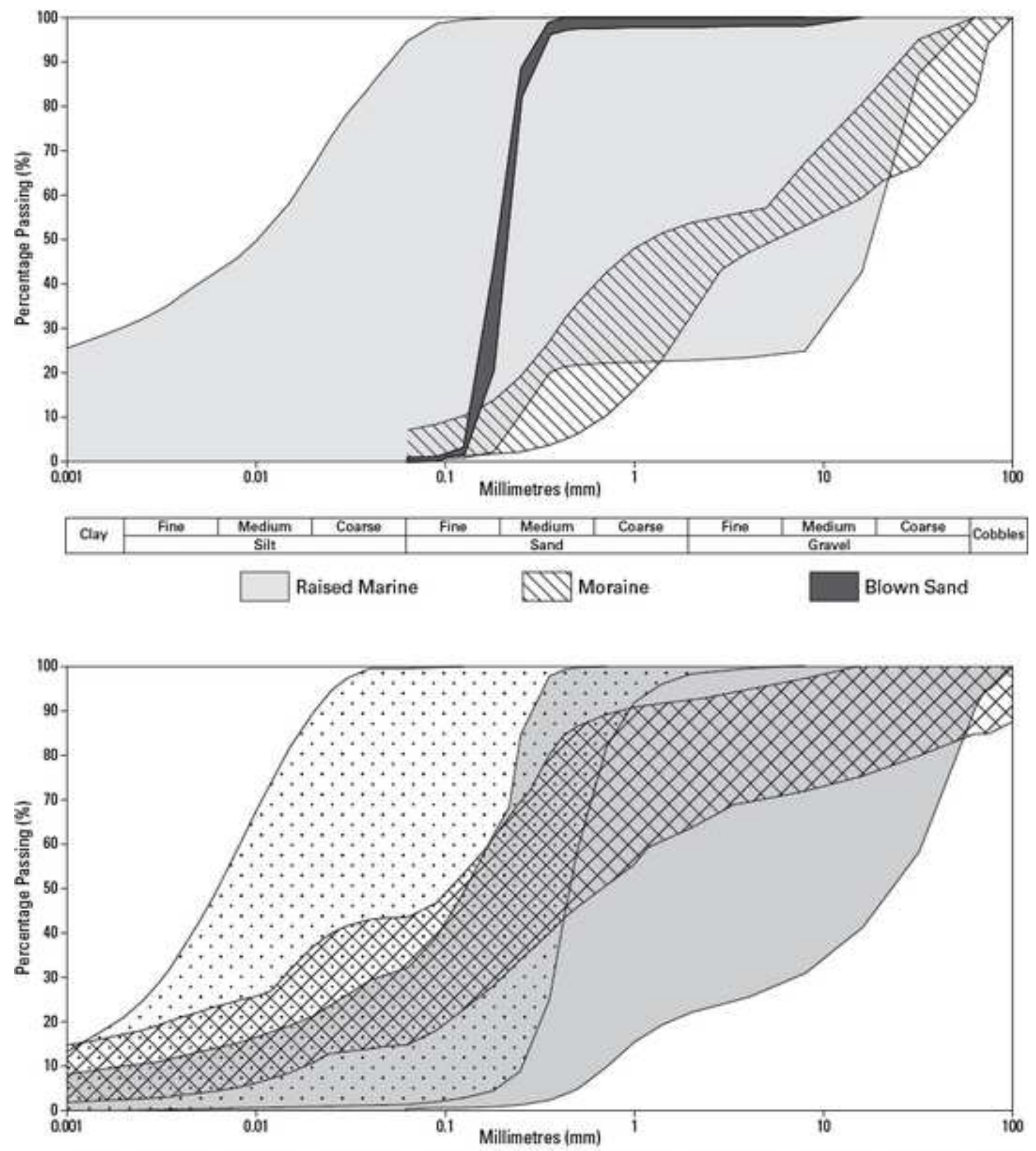

\begin{tabular}{|c|c|c|c|c|c|c|c|c|c|c|}
\hline \multirow{2}{*}{ Clay } & Fine & Medium & Course & Fine & Medium & Course & Fine & Modium & Coarse & \multirow{2}{*}{ Cobbles } \\
\hline & & Silt & & \multicolumn{3}{|c|}{ Sand } & \multicolumn{3}{|c|}{ Gravel } & \\
\hline
\end{tabular}




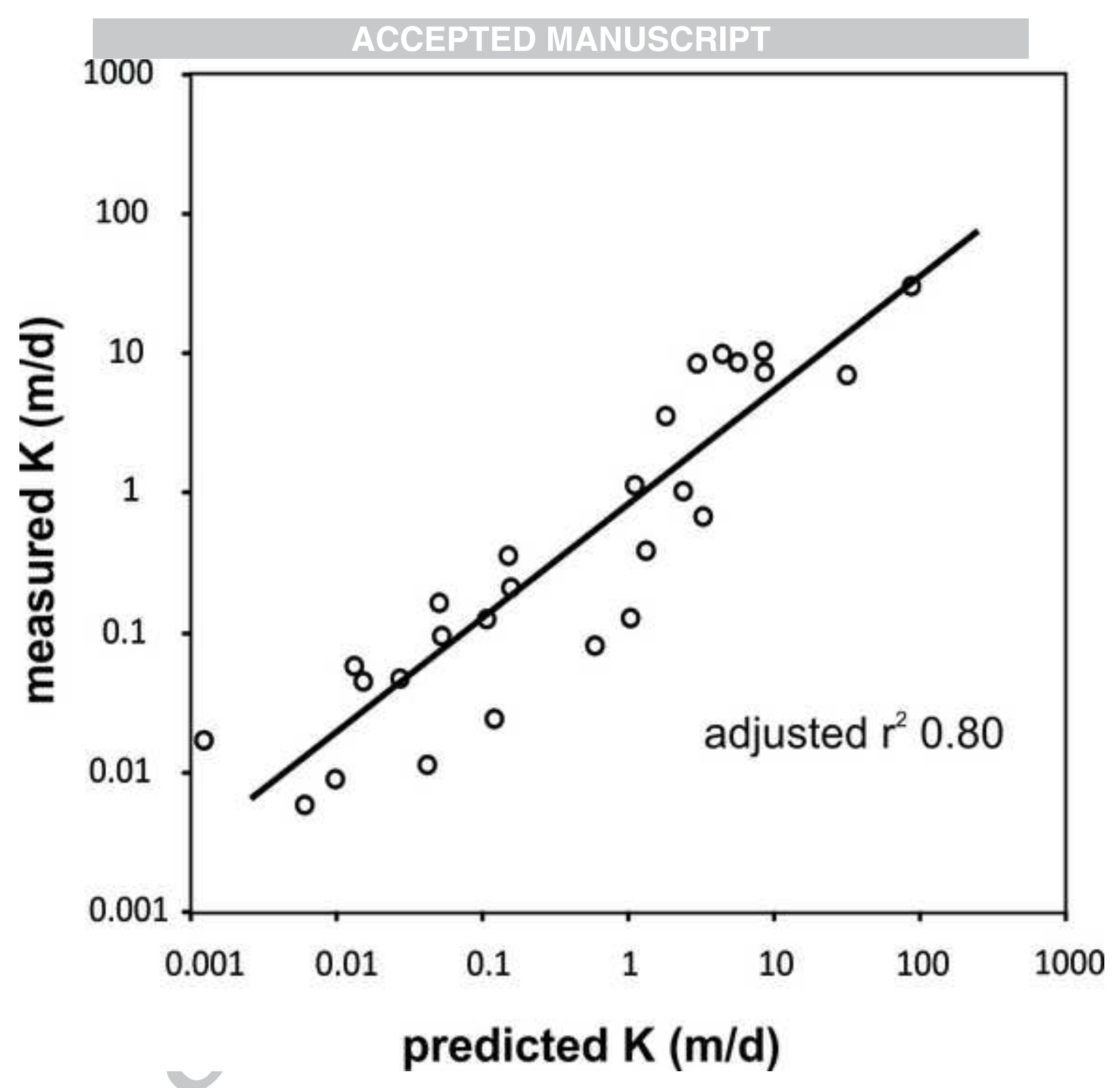




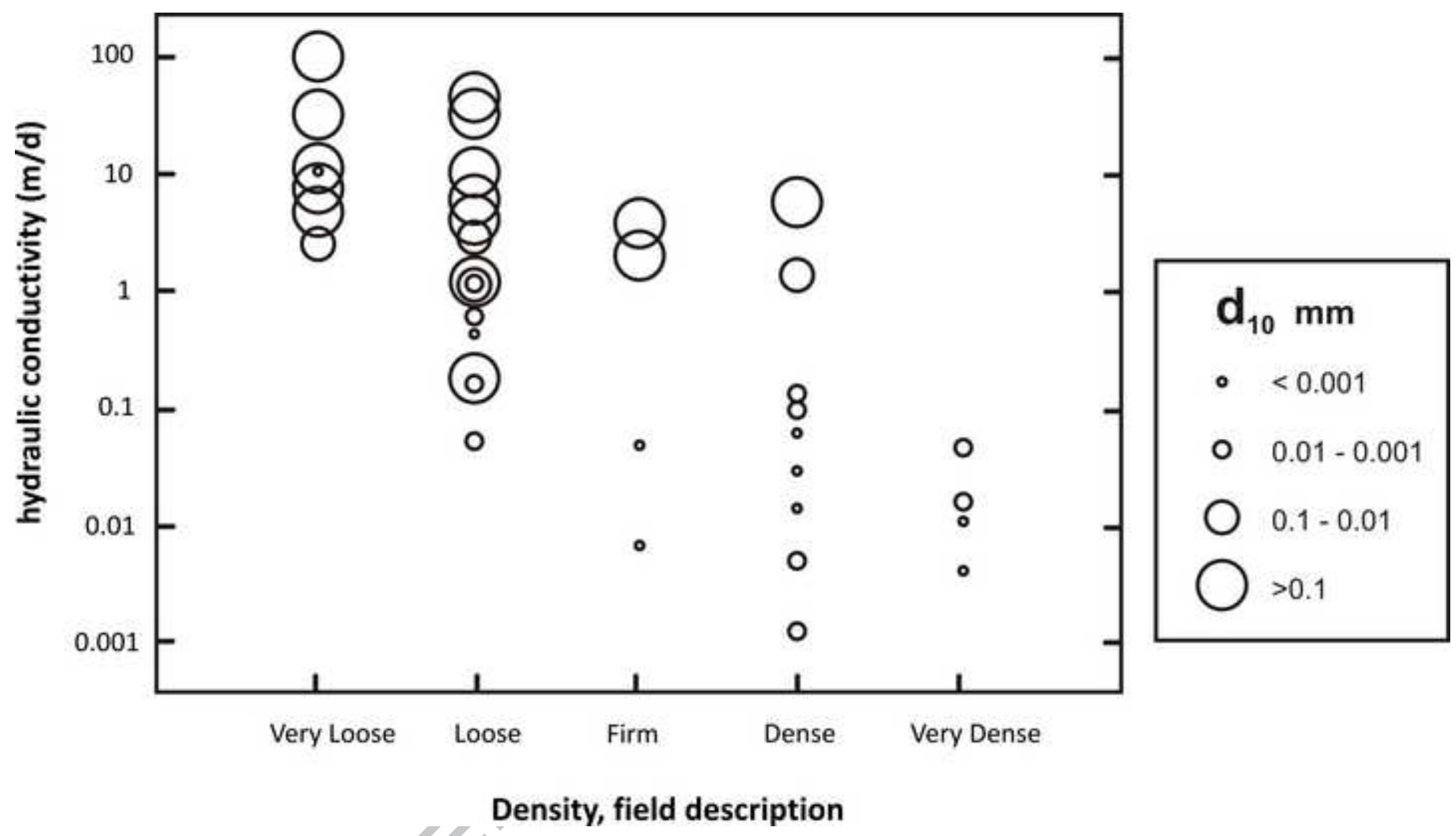




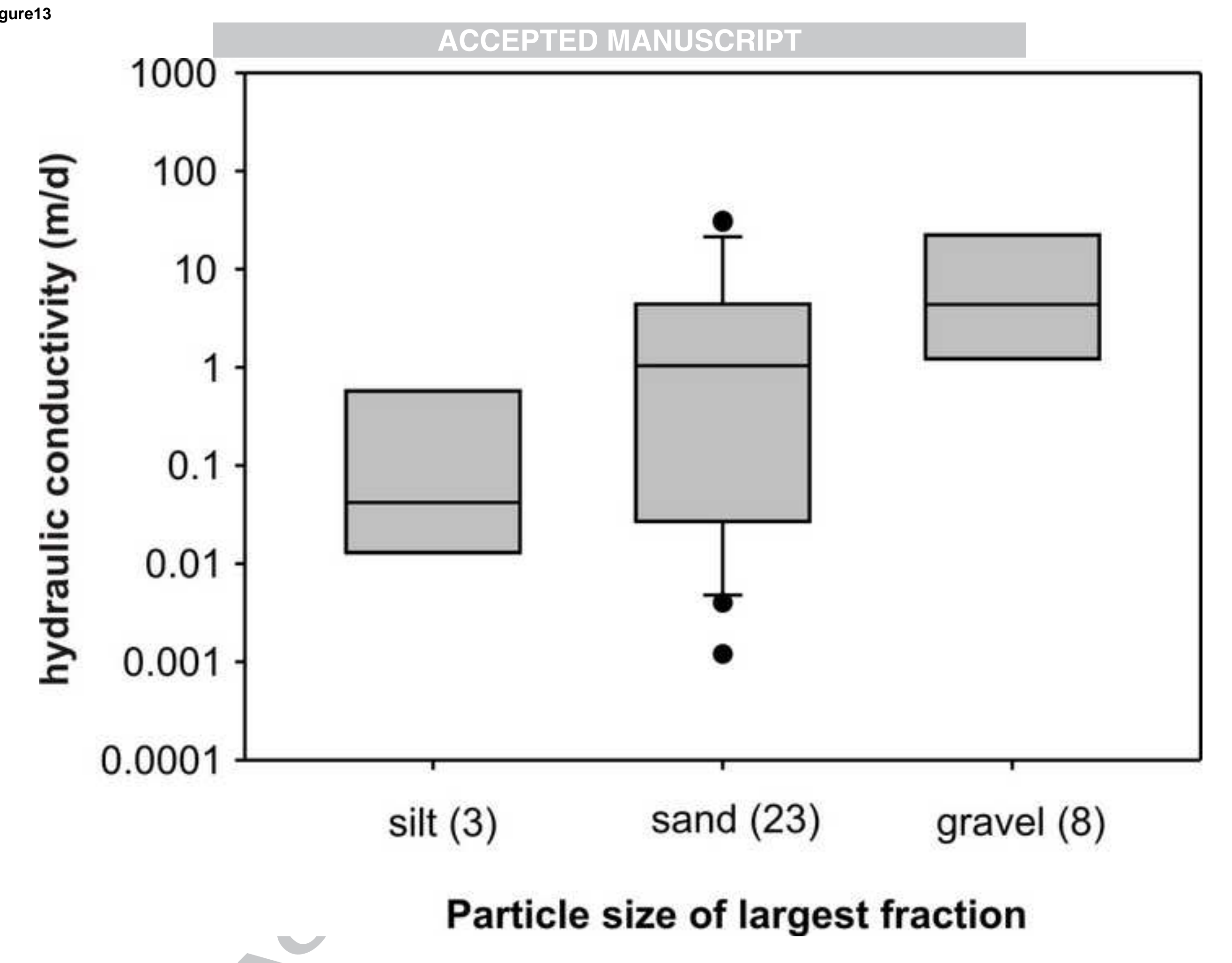

Particle size of largest fraction 


\section{Highlights}

We examine the permeability of superficial deposits in a heterogeneous catchment

$\mathrm{K}$ ranges from 0.001 to $>40 \mathrm{~m} / \mathrm{d}$, highest in glacial moraine, lowest in till

MLR showed that $K$ was related to $\log d_{10}$ and relative density with $r^{2}$ of 0.80

Material description of largest fraction had little predictive power of $\mathrm{K}$ 